\title{
El empleo público en Andalucía ${ }^{1}$
}

\author{
Federico A. Castillo Blanco \\ Catedrático de Derecho Administrativo. \\ Universidad de Granada.
}

\section{INTRODUCGIÓN: EL PROGESO DE GONSTRUGGIÓN DE LA BUROCRACIA PÚBLICA ANDALUZA.}

Cuando se observa la construcción de la burocracia pública en la mayoría de las Comunidades Autónomas bien puede afirmarse que la misma, a juicio de la mayoría de los observadores ${ }^{2}$, nació en cierto sentido lastrada por al menos dos elementos que han venido condicionando a lo largo de las últimas décadas su existencia: en primer término, porque la preocupación por parte de las Comunidades Autónomas se centró no tanto en construir una nueva Administración sino en el proceso de reivindicación competencial abierto con la aprobación de los distintos Estatutos; en segundo lugar, porque en muchos casos la inexistencia de un marco legal en el empleo público adaptado a las previsiones constitucionales que sólo surgirá en el año 1984 cuando los efectivos - en forma de contratados e interinos- y la forma de funcionamiento de la función pública autonómica, ya constituida en esos momentos en buena medida, condicionó decisivamente la forma de gestión a plantear en las futuras normas y la problemática a resolver ${ }^{3}$.

El texto que sigue es el expuesto en las JORNADAS DIEZ AÑOS DEL ESTATUTO DE AUTONOMÍA PARA ANDALUCIA (2007-2017), celebradas en Granada el 21 de septiembre de 2017 y Sevilla el 28 de septiembre, organizadas por el Instituto García Oviedo de la Universidad de Sevilla y el Gabinete Jurídico de la Junta de Andalucía.

PORRAS NADALES, A., "La administración andaluza entre modernización y clientelismo", Revista catalana de derecho público, núm. 18, 1994 y CÁMARA G., SÁNCHEZ, J. TERRÓN, J., El Gobierno y la Administración, Colección «Estatuto de Andalucía» (111), Barcelona, 1990, Ariel.

De todo el conjunto de problemas que han condicionado la construcción de nuestra burocracia pública, uno de los más graves y uno de los de mayor problemática judicial ha sido el de los funcionarios interinos. Como hemos visto el origen del problema se encuentra en el propio origen de construcción de la función pública autonómica: la necesidad de improvisar estructuras administrativas prácticamente nuevas, las resistencias de los funcionarios estatales a ser transferidos, las exigencias de autoafirmación de las nuevas organizaciones y otras motivaciones más cercanas al clientelismo explican el origen del problema como han puesto de manifiesto distinto autores (por todos MORILLO VELARDE «Noticias de la Administración Autonómica» a cargo de José I. Morillo-Velarde en Administración de Andalucía. Revista Andaluza de Administración Pública). De interés también resulta el trabajo del mismo autor "Competencias sobre régimen de las Administraciones Públicas (comentario al art. 47)", AA.VV., Comentarios al Estatuto de Autonomía para Andalucía, Dir. Muñoz Machado y Rebollo Puig, Civitas, 2008 
Asimismo, no hay que olvidar en este punto los vicios arrastrados en el período de trasferencias de competencias en los cuáles las de los recursos humanos constituyó un punto problemático que no contribuyó a otorgar una cierta racionalidad al sistema junto a la propia indefinición del modelo de integración territorial.

Muchos de estos obstáculos, sin duda, han quedado atrás, pero, en cualquier caso, los resultados han sido unas Administraciones autonómicas, miméticas en gran medida en cuanto a su diseño organizativo al modelo estatal (lo que en cierta medida era una consecuencia de la LOAPA), y una función pública en capas donde era, a juicio de la doctrina científica que se ha ocupado del tema, posible distinguir a los diversos colectivos atendiendo a su procedencia y régimen jurídico. El modelo finalmente resultante en ese momento, cuyos resultados seguramente no son achacables enteramente a las distintas leyes de función pública autonómicas sino a un conjunto de circunstancias diversas, ha venido marcado, según apunta ARENILLAS SAEZ, por elementos cómo los siguientes ${ }^{4}$ :

- Una estructura de personal, tan solo superada años después, que estaba formada básicamente por contratados e interinos ante las dificultades del período de transferencias (inclusive vacantes que se traspasaban por la propia Administración del Estado y el fracaso de las medidas incentivadoras para los funcionarios de la Administración del Estado) y para cubrir las lagunas que las necesidades en aumento de la nueva Administración demandaban sobre todo en lo que se refiere a puestos directivos.

Dicho problema ya se advirtió con ocasión de la primera Oferta de Empleo Público de la Junta de Andalucía (Decreto 23/1988, de 10 de febrero) que finalizó en una revisión de oficio de la misma tras la STC 67/1989, de 18 de abril y tuvo, también, como hito dos importantes sentencias del Tribunal Constitucional: la STC 27/1991, de 14 de febrero, que admitió la posibilidad de valoración razonable del tiempo servido como interino; y la STC 302/1993 que estimó los recursos de inconstitucionalidad frente a las Leyes 6/1988, de 17 de octubre y 7/1988, de 2 de noviembre rechazando la incorporación directa del personal contratado e interino sin efectuar prueba alguna.

Ante dicha situación fueron los mecanismos de negociación colectiva los que funcionaron. Dicha solución, el recurso a la negociación, habría de convertirse en el eje de la construcción del empleo público de Andalucía y no sólo en materia de consolidación del empleo público temporal

De esta forma, el Acuerdo de 5 de noviembre de 1990 (no publicado en el BOJA) que marcaba un compromiso de estabilidad para este personal hasta finalizar tres convocatorias de acceso al empleo público o el Acuerdo para modernizar la Administración de 1992 que añadía algo más y que se concretaba en que, presentados a las pruebas selectivas, si no superaban las mismas se negociarían los procesos que permitiesen la continuación de los mismos en puestos base con una relación laboral fija son una buena prueba, si nos referimos al personal interino, de lo expuesto.

Sin embargo, el problema no encontró una solución suficientemente satisfactoria y acontecidas esas tres convocatorias el contigente de personal interino seguía siendo importante. Ello desembocó en el Acuerdo de 1996 y, en otro posterior, de 27 de junio de 1999 (BOJA de 21 de septiembre).

4 AREnILLAS SAEZ, M., "Lo inevitable de la Función Pública Andaluza, Revista de Administración Pública de Andalucía, nº 8, 1991, págs. 103-136 
- Una organización administrativa, como ya se ha dicho, mimética a la del Estado, aunque bien es cierto que, como se ha puesto de manifiesto por la mejor doctrina, la interpretación del modelo competencial tampoco admitía grandes variables.

- Una estructuración de la función pública con un doble criterio organizativo: las relaciones de puestos de trabajo y, en forma complementaria, los cuerpos de funcionarios. Elementos ambos no siempre conciliables y que como ha acontecido en nuestra propia Comunidad Autónoma han obligado a buscar otros elementos organizativos como las denominadas áreas funcionales.

- La existencia en los primeros momentos de un fuerte colectivo laboral con capacidad negociadora, sin criterios algunos de adscripción que forzó a un tratamiento igualitarista en el tratamiento de los diversos colectivos de empleados públicos aunque con serias dificultades en algunos aspectos (como el acceso a la condición de personal permanente).

- Un deficiente funcionamiento de los sistemas de provisión de puestos de trabajo en el sentido de carencia regular de convocatorias y uso excesivo de los sistemas provisionales y de la libre designación para la provisión de los puestos de trabajo.

- Una función pública carente de directivos públicos y cuyas funciones no podía cubrir el personal eventual ya que éste no cubría sino funciones de confianza o asesoramiento especial.

En el caso de Andalucía, específicamente, son plenamente aplicables las consideraciones anteriores ${ }^{5}$. El retraso en las reformas del empleo público estatales que no llegaron a plasmarse hasta 1984 condicionó decisivamente la estructura de personal de nuestra Comunidad Autónoma que no pudo intentar la construcción de su burocracia pública hasta 1985 con ya, en esos momentos, una importante masa de personal interino que ha sido históricamente un factor clave y determinante en la dinámica de construcción del empleo público andaluz que paradójicamente se ha

\footnotetext{
5 Situación que se resumiría por el Defensor del Pueblo, quizás con excesivo dramatismo, en un Informe emitido en 1995 aludiendo a que se ponía de manifiesto una "inexistencia de planificación de la Función Pública Andaluza, que, después de más de quince años de experiencia autonómica y de casi diez desde la aprobación y entrada en vigor de la Ley 6/1985, de 28 de noviembre, de Ordenación de la Función Pública de Andalucía, no ha conseguido la consolidación". No pensamos, ciertamente, que la situación siete años después sea la misma. Lo cierto, desde nuestro punto de vista, y a pesar de las carencias a las que nos hemos referido con carácter genérico para todas las Comunidades Autónomas, es que culminado ya el proceso de transferencias, resuelto al menos en gran medida el problema del personal interino, y aconteciendo que la incorporación mayoritaria de personal se realiza a través de las ofertas de empleo público lo cierto es que existe una función pública ya consolidada. Necesitada de un nuevo impulso, con ciertos problemas en su funcionamiento, pero sin duda consolidada.
} 
agudizado de nuevo, a impulsos de la medidas adoptadas durante la crisis económica, en el empleo público andaluz. En todas, y esto es importante subrayarlo, las administraciones andaluzas.

La Ley 6/1985, de 28 de junio, de Función Pública de Andalucía, una ley fiel al modelo estatal con los condicionantes - reflejados en sus propias disposiciones- derivadas de la realidad precaria del empleo en ese momento existente en la Junta de Andalucía, ha sido objeto de modificación en variadas ocasiones. Las más significativas y estratégicas han acontecido a impulsos de las reformas a su vez acontecidas en el ámbito estatal. Así, a título de ejemplo, la que se introduce con la Ley 3/1991, de 28 de diciembre para adaptarla a la Ley de Medidas de Reforma de la Función Pública que había sido objeto de modificación tras la sentencia 99/1987, de 11 de junio del Tribunal Constitucional, la Ley 17/1999, de 28 de diciembre, que incorpora las modificaciones producidas en la Oferta de Empleo Público, o la recientemente acontecida con la Ley 2/2016, 11 mayo, en materia de valoración de la antigüedad a efectos de méritos incluyendo los servicios prestados como interino. Como puede observarse reformas puntuales a las que deben añadirse específicas previsiones realizadas a través de la legislación presupuestaria o de acompañamiento de los presupuestos.

En suma, y aunque nos refiramos más adelante de forma detallada a estos extremos, si puede decirse que el desarrollo normativo de las previsiones establecidas en los dos Estatutos de Autonomía que han regido la vida institucional de Andalucía se ha movido a impulsos de dos elementos: un elemento fáctico, la estructura del personal de la Junta de Andalucía con un importante contingente de personal interino; y un elemento jurídico, las reformas acontecidas en el marco básico de la legislación estatal. Ciertamente se ha echado de menos un impulso propio, respetuoso de la normativa básica pero adaptado a las necesidades de la sociedad andaluza, y con una definición estratégica singular alejada de situaciones coyunturales derivadas del personal existente, sobre todo si se tiene en cuenta el peso específico de nuestra Comunidad Autónoma y el factor de impulso que en la economía andaluza representa la misma.

En la actualidad, y junto a problemas subsistentes e insuficientemente resueltos, se han agravado dos muy relevantes, a saber: el primero de ellos común a todo el país, la temporalidad del empleo público y es que en Andalucía, durante los ocho últimos años de crisis, con la tasa de reposición limitada por las medidas adoptadas en el ámbito estatal, la tasa de interinidad en la Junta se ha disparado del 3 al 13,5\% en la educación pública, y roza hasta el 25\% en la sanidad; y en segundo lugar, su envejecimiento y, en este sentido, simplemente un dato, en este caso referido a la AGE pero que en gran medida es extrapolable a nuestro empleo público, lo pondrá de manifiesto: el 15’18\% de los empleados públicos tiene más de 60 años, el 74,62 \% se encuentra 
entre los 40 y los 59 años, y sólo el 10,09 \% tiene menos de 40 años ${ }^{6}$. Digamos algo más de estas disfunciones que hoy están presentes en nuestro empleo público.

Es conocido que, en 2005, la Comisión Europea ya advirtió a España de que la Administración pública tenía sumamente elevada la tasa de empleos temporales. Para corregirlo Bruselas exigió medidas urgentes que ayudaran a estabilizar el trabajo de su plantilla y redujeran la tasa de interinidad al 8\% en 2012. Educación y Sanidad estaban en el punto de mira, no por otra razón sino porque son los servicios públicos con mayor número de trabajadores. En Andalucía, por aquel entonces, el porcentaje de profesores interinos rondaba el $21 \%$, siendo una de las plantillas más envejecidas del país, y en el ámbito sanitario la cifra era superior al 25\%. Y, desde luego, algo se avanzó desde ese momento en este concreto aspecto.

No obstante, durante los últimos ocho años de crisis económica, España ha vivido sometida a fuertes políticas de austeridad, medidas de consolidación fiscal y de recortes en el gasto público. Una de las decisiones más duras, impuesta primero por el Gobierno de José Luis Rodríguez Zapatero y prorrogada los últimos cinco años por el gabinete de Mariano Rajoy, han sido los límites a la tasa de reposición de efectivos, que han impedido a las comunidades autónomas cubrir el 100\% de las vacantes de médicos y maestros que salían del sistema (se jubilaban o morían). Esta medida no sólo cerró el grifo de las ofertas de empleo público, sino que también disparó la tasa de interinidad y de empleo laboral temporal en la Administración y provocó un

6 Otras características de nuestro empleo público son:

- El empleo público se concentra en los servicios del Estado del Bienestar, especialmente en los servicios educativos y sanitarios, que representan el 40\% del total (Comunidades Autónomas: 582 efectivos en el Área de Docencia no Universitaria, y 490.509 en Instituciones Sanitarias del Sistema Nacional de Salud).

- Importante presencia femenina en el empleo público: más de la mitad de sus integrantes son mujeres (55,29\%). Mayor porcentaje en el personal de las Comunidades Autónomas (69,07 \%), dado que en las áreas de Sanidad y Educación, competencias de las CG.AA., trabajan las mujeres en porcentajes muy superiores a la media, y que es la Administración de más reciente creación y, por ello, refleja la creciente incorporación de las mujeres al mercado de trabajo que ha tenido lugar en las últimas décadas. La menor presencia de mujeres en la Administración Pública Estatal (30,68 \%) se explica porque en las Fuerzas Armadas $(12,55 \%$ y en las Fuerzas y Cuerpos de Seguridad del Estado $(9,94 \%$ ) existe todavía un abrumador predominio masculino. El porcentaje de mujeres en la Administración General del Estado (51,77 \%) es ligeramente inferior al del conjunto de las Administraciones Públicas.

- Se ha producido una importante "laboralización” del empleo público en España: el 23,13 \% de los empleados públicos son personal laboral (713), siendo mayoritarios es la Administración local (53,32 \%).

- El personal de la Administración Pública Estatal supone menos de la cuarta parte del total de empleados públicos (la Administración General del Estado, en sentido estricto, supone únicamente el $8,19 \%$ del total). Estatal.

- El personal de las Comunidades Autónomas dobla ampliamente al de la Administración Pública

- La Administración local cuenta con un número de empleados superior al de la Administración Pública Estatal. 
mayor envejecimiento de las plantillas. Aun aceptando que se consigan los objetivos previstos, no está de más de nuevo recordar, como ya han hecho especialistas en materia de empleo público como SANCHEZ MORÓN, PALOMAR OLMEDA, MAURI MAJÓS, JIMÉNEZ ASENSIO O KOLDO ECHEBARRÍA, etc. que este tipo de medidas tienen un no deseable doble efecto. Quiero decir con ello que, junto a intentar lograr contener el déficit, introducen y exacerban disfunciones ya existentes, básicamente por su carácter lineal y uniforme, en la estructuración y en la gestión del empleo público ${ }^{7}$, en la motivación de los empleados públicos y si se mantienen a largo plazo conducen a una selección adversa y a una fuga de capital institucional en lo que se refiere a la construcción de una burocracia pública, en palabras de RANDMAN, "altamente profesional, imparcial políticamente, fiable, eficiente y receptiva".

La crisis, por tanto, revertió todo el trabajo que se había realizado entre 2005 y 2012 para estabilizar el empleo en las administraciones, y recuperó las cotas de temporalidad anteriores al 2005. Hasta ahora, nunca antes una administración había estado tanto tiempo seguido sujeta a un límite tan sumamente estricto de la tasa de reposición con las consecuencias ya aludidas.

Vayamos al haber. La ventaja fundamental de nuestra burocracia pública, como ha puesto de manifiesto SANCHEZ MORÓN ${ }^{9}$, es la profesionalización de nuestro régimen de empleo público que, a pesar de los pesares, se ha conseguido preservar en lo esencial desde hace casi un siglo, no obstante la preferencia por el criterio de la confianza política para el nombramiento de un número creciente de cargos de nivel superior y de ciertas disfunciones clientelares, más frecuentes en unas Administraciones que en otras.

Téngase en cuenta que, como ha advertido dicho autor, la profesionalidad va unida a una estabilidad sustancial en el empleo, que es prácticamente absoluta para el personal funcionario y también sigue siendo la regla general de facto para el personal laboral, a pesar del elevado porcentaje de empleados públicos temporales que existe en las Administraciones autonómicas y locales y de las posibilidades de despido

Como ha puesto de relieve BAYLOS, A., Sobre la reducción salarial de los Empleados Públicos, Informes de la Fundación, $n^{\circ}$ 19, Fundación $1^{\circ}$ de mayo, 2009, página 5, "El salario expresa en términos convencionales el valor del trabajo. Es cierto que no todo el valor realizado, pero si el que concierne a la productividad media de la rama de producción y que se materializa en un cierto valor social de la profesión o del trabajo materialmente prestado por determinadas personas en una jerarquía salarial que es también social. La reducción del salario de un trabajador implica por consiguiente un juicio negativo sobre el valor de su trabajo que pierde prestigio social y reduce su posición en la jerarquía salarial".

8 RANDMA-LIIV, T. (2002). "Small States and Bureaucracy: Challenges for Public Administration." Trames 6(4): 374-389.

9 SÁNCHEZ MORÓN, M.: La administración tras la crisis: el empleo público. SUMAS 2012, Ayuntamiento de Vitoria-Gasteiz, pp. 1-12, 2012. 
colectivo por razones económicas o de organización que confirma - más que abre- la última reforma de la legislación laboral. La profesionalidad supone asimismo que la mayoría de los empleados públicos, seleccionados mediante pruebas objetivas, están preparados y cualificados para desempeñar sus tareas adecuadamente, y que gozan de oportunidades de formación permanente y de ciertos estímulos para el desarrollo de su carrera en el sector público. Naturalmente, estas cualidades positivas deberían conservarse a toda costa e incluso garantizarse en mayor medida que hasta ahora, siempre sobre la base de los criterios de mérito y capacidad.

No es menos cierto, sin embargo, que existe un acuerdo mayoritariamente generalizado en la doctrina, y en los gestores de recursos humanos, de las carencias que el sistema presenta (SANGHEZ MORÓN, JIMENEZ ASENSIO, GORRITI, CANTERO, GARRIDO GUENCA, etc.). Por resumirlo, y a juicio del primero de los autores citados, sigue siendo un sistema demasiado rígido, poco eficiente o productivo y en buena medida improvisado y desequilibrado. Y sigue poniendo de relieve que "la rigidez y relativa ineficiencia vienen de lejos, ya que en la regulación del régimen del empleo público ha pesado habitualmente más la garantía de los derechos de los funcionarios y, por asimilación, de otros empleados - esto es, sus demandas corporativas o gremiales- que la preocupación por la eficacia del servicio público. El desequilibrio y la improvisación se acentuaron en las décadas de expansión y crecimiento cuando ha habido que erigir nuevas Administraciones públicas por razón de la descentralización, organizar los servicios universales del Estado del Bienestar y cuando se ha querido dar respuesta política a numerosas demandas sociales $-\mathrm{y}$ territoriales- no todas ellas razonables ni atendibles sin incrementos exponenciales del gasto público"lo.

10 Expone SANCHEZ MORÓN en el trabajo citado que "Lo cierto es que, hasta hace muy poco tiempo, ya entrada la crisis económica, el número de empleados públicos no había dejado de aumentar, a la par que mejoraban continuamente sus derechos retributivos y laborales - hay quien los llama privilegios-, sin la contrapartida de una mayor productividad, inclusive medida en términos elementales de tiempo de trabajo. Estos defectos y problemas no se han afrontado nunca de manera efectiva y menos aun rigurosa, a pesar de la crítica doctrinal, de las recomendaciones de no pocos informes oficiales y de las promesas electorales de los partidos.

El último intento general de abordarlos, que se puso en marcha con la preparación del EBEP, ha sido en gran medida y a la postre un intento fallido, pues muchas de las propuestas que se formularon por la Comisión creada al efecto no llegaron al texto de la Ley o bien se recogieron en ella de manera ambigua o descafeinada, como meras posibilidades a concretar por una legislación de desarrollo que hasta ahora no ha visto la luz de forma generalizada. Desde luego no en Andalucía. Frente al impulso reformista prevaleció una lógica conservadora del modelo existente y los intereses propios de los partidos y de los sindicatos más representativos. Creo que esto es historia sabida, por más que inmediata, en la que no merece la pena detenerse.

Lo que si ha sucedido es que la crisis nos reveló, a la opinión publica en general, algunos "excesos". Había servicios duplicados sin ventaja aparente para el ciudadano. Se ha puesto de relieve una excesiva politización de la Administración pública y del régimen del empleo público, que ha llevado a multiplicar 
En el momento actual, la Junta de Andalucía ha aprovechado que el límite de la tasa de reposición parece tener los días contados para presionar al Gobierno del Estado, instándole a que regule la convocatoria de una oferta de empleo extraordinaria masiva con el objetivo de dar estabilidad a miles de interinos de la Administración, sobre todo médicos y profesores. El Gobierno de Andalucía se ha apresurado a marcarse el tanto, anunciando que con esta fórmula (a coste cero según se dice) blindaría la plaza de 40.000 maestros interinos y eventuales del Servicio Andaluz de Salud (SAS). Su socio de legislatura, Ciudadanos, ya le ha advertido de que estará vigilante, y que no aceptará que se blinde la plaza de eventuales en la Administración "por la puerta de atrás". Ya veremos que sucede, pues la mayoría de estos procesos se pondrán en marcha ahora, aunque las vías abiertas en la legislación presupuestaria del Estado de 2017 para esta cuestión ya han quedado francas y disponibles.

En realidad éste no es un debate exclusivamente andaluz. Y, de hecho, formó parte de la negociación entre el Ministerio de Hacienda y las Comunidades Autónomas en el marco de la Conferencia de Presidentes. Y como se sabe se ha saldado con una flexibilización de la tasa de reposición de efectivos y con la apertura de distintos mecanismos para consolidar el empleo público temporal que lucen ya en la Ley de Presupuestos Generales del Estado de 2017.

El debate, en estos momento, es el mismo de siempre: ¿ise usará o no un procedimiento ordinario de oposición para dar estabilidad a su plantilla? ¿cómo se primará la experiencia? ¿asistiremos a procesos de selección meramente formales dirigidos a consolidar a quienes ya prestan servicios?. Las declaraciones, en este punto, no dejan lugar a dudas y son del tipo: "Queremos garantizar que no va a haber una descapitalización del sistema sanitario y educativo, que no vamos a perder a profesionales con experiencia".

En cualquier caso, y conviene advertirlo, este reto que se abre en estos momentos no es, a pesar de su relevancia, el principal problema de nuestro sistema de empleo público y algunos de los apuntados más arriba destacarían en el ranking.

servicios y unidades administrativas contra toda lógica económica y de buena administración, y que ha dado lugar a numerosas prácticas clientelares, con menoscabo de los principios constitucionales que rigen el empleo público, y ha impedido o dificultado el desarrollo de un modelo gerencial de recursos humanos en las Administraciones públicas.

Se ha evidenciado también que entre los derechos adquiridos por los empleados públicos -incluida la seguridad en el empleo y en el propio puesto de trabajo- y sus deberes y obligaciones -particularmente las relativas a jornada y tiempo de trabajo-, existe una asimetría muy alejada de los estándares del sector privado.

Asimismo, y bien que es doloroso ponerlo de manifiesto, ha quedado patente que el régimen de la negociación colectiva en el sector público, tal como ha sido entendido y practicado por los sindicatos y aceptado de hecho por los gobernantes, contribuía decisivamente a esos desequilibrios y constituía no ya un obstáculo insalvable para la contención del déficit público, sino una de las razones fundamentales por las que se ha disparado, etc". 
Ahora vayamos a lo jurídico ¿de qué instrumentos disponemos para afrontar los retos del empleo público en la actualidad?.

\section{TITULOS CONSTITUCIONALES HABILITANTES DE LA COM- PETENCIA ESTATAL Y AUTONOMICA EN MATERIA DE FUNCION PUBLICA.}

Un Estado descentralizado como el que preconiza la Constitución de 1978 necesariamente ha de manifestarse, y ello como parte del núcleo irreductible básico en que se basa, en la posibilidad por parte de las Administraciones públicas territoriales de articular su estructura orgánica y, por ende, su función pública como elemento éste último instrumental para la consecución de los objetivos expresados, con carácter genérico, en el abanico competencial a éstas atribuido.

Nuestro país, con poca tradición descentralizadora, hubo de enfrentarse en esta materia tras la aprobación del texto constitucional a delimitar qué elementos del empleo público constituían un vértice central que debía ser común a todas las burocracias públicas pertenecientes a los entes territoriales y, por ello, de necesaria regulación estatal y, de otro lado, qué otros elementos componentes del Estatuto de la función pública, no estructurales en consecuencia del sistema de empleo público total, debían en todo caso resultar atribuidas al resto de Administraciones públicas. Lo cierto es que, si lo analizamos con la perspectiva que el tiempo nos ofrece, el ejercicio por parte del Estado de sus competencias ha sido excesivamente intenso en esta materia, seguramente por la inercia histórica a la hora de interpretar el texto constitucional, resultando un modelo final que apenas, si salvamos el caso de Navarra, difería entre sí no sólo en aspectos estructurales sino, lo que sí podría resultar cuestionable, en el resto de los elementos que apenas resultan diferenciados.

Las atribuciones competenciales establecidas en el artículo 149 CE asignan al Estado la legislación básica en materia de función pública. De esta forma, el art. 149.1.18 de la Constitución reconoce al Estado la competencia exclusiva para dictar las bases del régimen jurídico de la Administraciones Públicas. El Tribunal Constitucional, en su conocida sentencia 5 de agosto de 1.983, declaraba, analizando el alcance del concepto, que del precepto derivaba una doble competencia estatal: " 1 " Competencia para regular los aspectos básicos de la situación personal de los funcionarios públicos; es decir, de la denominada relación de servicio, contenido indiscutible del régimen estatutario, y $2^{a}$ competencia para regular los aspectos esenciales de la organización de la burocracia de las Administraciones Públicas, pues la expresión "régimen jurídico" contenida en el precepto constitucional no se refiere exclusivamente al procedimiento y al régimen de recursos, como ha señalado este Tribunal Constitucional en su sentencia 32/1.981, de 28 de julio, y ha de entenderse incluida también en ella la regulación básica de la organización de todas las Administraciones públicas". 
Señalando, específicamente en un párrafo posterior, la sentencia referida respecto de las competencias de las CC.AA. que "cada Comunidad Autónoma ha de respetar, en cualquier caso, las bases que, de acuerdo con lo establecido en el artículo 149.1.18 de la Constitución, corresponde fijar al Estado".

De esta forma, la expresión régimen estatutario de los funcionarios incluye a todas las Administraciones públicas (SSTG 99/1987, de 11 de junio y 235/1991, de 12 de diciembre), y en éste ha de entenderse incluido los principios estructurantes del sistema de acceso al empleo público y el ascenso a nuevos cargos dentro de la organización así como la pérdida de la condición de funcionario público (SSTC 193/1987 y 207/1988), los procedimientos en virtud de los cuales los empleados públicos participen en la fijación de sus condiciones de trabajo (STC 98/1995, de 29 de julio), las incompatibilidades del personal al servicio de las Administraciones Públicas (STC 179/1989, de 2 de noviembre) y el sistema retributivo (SSTC 63/1986, de 21 de mayo y 103/1997, de 24 de mayo). Específicamente, respecto de este último, la jurisprudencia constitucional citada establece que las bases del régimen estatutario de los funcionarios pueden extenderse a incluir en ellas previsiones relativas a las retribuciones de los funcionarios públicos, comunes a todas las Administraciones Públicas, y a la cuantía de éstas, lo que, a su vez, hallaría fundamento en los principios constitucionales de igualdad y solidaridad.

Sin embargo, y como SANCHEZ MORON ha explicado fundadamente, la normativa básica atribuida al Estado no necesita extenderse a todos los extremos de un Estatuto del empleo público ni tampoco requiere la misma profundidad en todos ellos y si observamos las tendencias existentes en el empleo público dentro del Derecho comparado podremos observar también cómo la descentralización en esta materia ha sido un elemento principal de las reformas administrativas que se han emprendido $^{11}$. Efectivamente, desde nuestro punto de vista, puede decirse que la estructuración del empleo público español tras la Constitución española, y aún cuando esta había introducido elementos novedosos en el sistema, no varió en lo esencial, seguramente por la fuerza de la inercia preconstitucional, las competencias para la definición del modelo de empleo público que ha seguido siendo definido prácticamente de forma integra por el Estado.

Lo cierto es que ese período ha revelado que esta perspectiva de construcción de la burocracia pública no es la única que puede realizarse. Y es que, en efecto, la lectura de los títulos competenciales constitucionales realizada en ese momento presentaba, desde nuestro punto de vista, ciertas carencias y, en cierto sentido, resultaba lastrada por la visión preconstitucional de definición de lo que haya de entenderse

11 SANCHEZ MORÓN, M., Derecho de la Función Pública (10ª edición), Tecnos, Madrid, 2017. 
por empleo público. Inclusive, podría añadirse, que era poco operativa para el funcionamiento eficiente del sistema de gestión de los recursos humanos en las Administraciones públicas territoriales tras haberse casi completado el ciclo de transferencias competenciales a éstas.

En este sentido, la interpretación que haya de realizarse de los títulos competenciales previstos en los artículos 149.1.18 y 149.1.13 CE ha de ponerse en necesaria conexión, en materia de función pública, con las competencias atribuidas a las Comunidades Autónomas en el artículo 148.1.1 relativo a las facultades que las mismas ostentas en materia autoorganizatoria y de gestión y, asimismo, con las derivadas del reconocimiento de autonomía a las entidades locales en el artículo 137 CE que necesariamente han de tener una importante expresión en esta materia que está en íntima conexión con aquél.

En consecuencia, el sistema integral de función pública o de empleo público habría de venir alimentado en sus elementos estructurales por el Estado dadas las exigencias del modelo constitucional de empleo público, pero a éstas consideraciones tendrían que unirse las derivadas de la organización propia de las Comunidades Autónomas y de los Entes Locales -o inclusive de otras Administraciones públicas no territoriales- que sumarían a este modelo otros elementos que lo complementarían singularizándolo y adaptando este al marco competencial propio. Así las bases del régimen estatutario de los funcionarios públicos, como competencia normativa estatal, solo alcanzarían al primer aspecto mientras que el segundo, lógicamente y de forma natural, estaría en manos del resto de Administraciones públicas.

Y es que el papel asignado al Estado, como organización pública directiva y planificadora a nivel global, dista en gran medida del papel que Comunidades Autónomas y Entes Locales parecen llamados a jugar como entes territoriales con competencias de ejecución muy relevantes en ámbitos claramente diferenciados de lo que podríamos denominar Administración tradicional. Y a ello debe responder también el sistema de función pública que no es abarcado de forma completa por los aspectos estatutarios básicos que sólo han de dirigirse a garantizar los aspectos más relevantes de dicha relación (los atinentes al modelo de función pública derivados de los artículos 23, 28 y $103.3 \mathrm{CE}$ ), sino que ha de responder, a fin de evitar rigideces y dificultades en su aplicación, a la organización y competencias que a éstas se les atribuyen permitiéndoles un amplio campo de definición. Es decir, concluyendo la idea apuntada, el sistema de función pública en cada Administración territorial vendría compuesto por los elementos derivados del sistema estatutario común a todos los funcionarios públicos al servicio de todas las Administraciones públicas, pero también, y aquí radica la clave para la correcta comprensión del problema planteado, por un grueso de materias atribuida al resto de los entes territoriales distintos del Estado 
destinada a singularizar el sistema de función pública articulado a nivel global a las exigencias que resultan de las competencias atribuidas a cada Administración pública y la organización establecida por éstas a fin de darles cumplimiento y eficaz prestación.

Ciertamente, y como ha reflejado NIETO, la "Función Pública se encuentra sometida a dos tensiones contrarias: la uniformizadora, que invoca la racionalidad, y la fraccionaria, que se apoya en la realidad. Pero la verdad es que la uniformización responde con frecuencia a inspiraciones que, so capa de racionalidad, lo que ocultan es la abstracción. $Y$ tan contraproducente es la integración en un mismo grupo de elementos heterogéneos como la descomposición de un grupo homogéneo en fracciones distintas", diagnóstico preciso que nos releva de realizar comentario alguno más y que refleja claramente la tensión referida en párrafos anteriores ${ }^{12}$.

\section{LA PROPUESTA REALIZADA POR EL ESTATUTO BÁSICO DEL EMPLEADO PÚBLIGO Y SU NEGESARIO DESARROLLO.}

La aprobación del Estatuto Básico del Empleado Público supuso, en nuestro sistema de relación bases-desarrollo, una nueva propuesta legislativa. Como es suficientemente conocido, las propuestas formuladas partían de elaborar un Estatuto Básico de menor extensión, que contuviese normas de aplicación directa, pero con una eminente función directiva, susceptible de ser adaptado por la legislación de desarrollo a las características propias de cada Administración, de acuerdo con las opciones de los órganos parlamentarios y de gobierno competentes; un Estatuto, como se indicaba en el Informe que precedió a éste realizadas de forma previa por una Comisión constituida al efecto, "que contenga solamente aquello que convenga regular para el conjunto de las Administraciones Públicas"13.

12 NIETO, A., "La nueva organización del desgobierno", Ariel, Barcelona, 1996, pág. 152.

13 Con este mismo sentido ha de operar, en opinión de MONTILLA MARTOS, J.A. "La legislación básica tras las reformas estatutarias", Revista Española de Derecho Constitucional, n 78, 2006, pág. 118 , la legislación básica ya que en su opinión “...las bases delimitadoras de las competencias autonómicas deben constituir una regulación de mínimos. Ese mínimo normativo tiene, a su vez, un rasgo estructural, al menos con carácter tendencial, cual es su carácter principialista, no tanto como exigencia constitucional sino funcional, esto es, como límite estructural al detallismo. El carácter normativo de lo básico, de forma que pueda ser directamente aplicable y no a través de las normas autonómicas, no obsta, a mi juicio, para sostener que la estructura de esas normas debe evitar el tratamiento detallado y hacer más hincapié en los criterios ordenadores de carácter general". Debe subrayarse que ciertamente, y aún cuando con carácter general lo básico ha de establecerse mediante ley, la extensión e intensidad de las bases puede variar por razón de la materia (STC 50/1999, de 6 de abril); que la noción material de bases justifica su establecimiento por vía reglamentaria o, excepcionalmente, mediante actos ejecutivos (SSTC 1/1982, de 28 de enero; 57/1983, de 28 de junio; 48/1988, de 22 de marzo; 179/1992, de 13 de noviembre; 197/1996, de 28 de noviembre, entre otras). 
En el sentir de la Comisión aludida el Estatuto debería constituir una norma básica que permitiese a todas y a cada una de las Administraciones, sobre la base de un sustrato común de derechos y deberes de los empleados públicos, acometer las reformas específicas que requiriese la modernización de su sistema de empleo público permitiendo adaptar su modelo de empleo público a los requerimientos y las finalidades de su propia organización. Las propuestas de la Comisión, por tanto y en esta línea, acogían distintas posiciones de lo que debía ser entendido como básico, verbigracia $^{14}$ : en unos supuestos, el Estatuto debería contener normas de obligado cumplimiento; pero en otros casos dichas normas no tendrían sino un carácter habilitador, de directriz o meramente orientativo. Inclusive el texto final, y según lo ya expuesto, acogió otras funciones de lo denominado básico, ciertamente más discutibles, como norma o menú dispositivo o de configuración de un estándar mínimo o supletorio en otros supuestos ${ }^{15}$.

El resultado inmediato de esta propuesta legislativa se tradujo en separar netamente la función constitucional específica de ordenación competencial atribuida al Estado a través de la legislación básica, de la función de regulación ordinaria en el ejercicio de sus competencias que no puede ni debe confundirse con la anterior si bien no era ello lo que había ocurrido hasta ese momento ${ }^{16}$. Se ha producido, con ello y a efectos prácticos de lo que en este punto interesa subrayar, un efecto indirecto en el legislador estatal de contención a la hora de establecer las bases del sistema de empleo público ${ }^{17}$.

En este sentido, el EBEP utilizó, hagamos un paréntesis ahora en cuanto al acierto de sus soluciones, una técnica novedosa en la plasmación y delimitación de esa legislación básica. De un lado, como ya se ha adelantado, el legislador del EBEP

14 Puede verse a este respecto TORNOS MAS, J."Sistema de Distribución de Competencias", AAVV, "El Funcionamiento del Estado Autonómico", MAP, Madrid, 1999, pp 158 y ss.

15 Véase, a título de ejemplo, la estructura de las retribuciones complementarias. Lo que, por otro lado, tampoco ha sido una novedad en este texto legal ya que, como puede comprobarse, el Estatuto Marco del Personal Estatutario de los Servicios de Salud también así lo contempla.

16 En torno a este punto es muy acertado desde nuestro punto de vista el análisis que realiza BALAGUER CALLEJÓN, F., "Las cuestiones competenciales en los actuales procesos de reforma de los EA", $R G D C, \mathrm{n}^{\circ} 1,2005$.

17 Si bien se discute si las previsiones estatutarias determinan o no un cierto "blindaje" de las competencias autonómicas, mi opinión en este punto es que el legislador básico estatal no resulta obligado por la delimitación negativa efectuada. Como ha expuesto MONTILLA MARTOS, J.A., en la obra citada, "aún cuando el Estatuto no pueda condicionar lo básico, la reforma estatutaria incide en ese proceso de delimitación, aunque de forma indirecta, pues al detallar con exhaustividad las competencias autonómicas condiciona la delimitación de lo básico que corresponde al Tribunal Constitucional. Y eso por dos razones: en primer lugar, por la alteración del parámetro de constitucionalidad que supone y, en segundo lugar, por lo que podemos denominar la doble deferencia del Tribunal, no sólo al legislador básico sino también al Estatuto". 
segrega la función de legislador básico de la de legislador ordinario. Es decir, sólo y exclusivamente se refiere a aquellos aspectos que considera estructurales del sistema de empleo público de todas las Administraciones públicas y remite a leyes del Estado y de las Comunidades Autónomas el desarrollo de dichas previsiones a fin de que completen el modelo de empleo público que, por definición constitucional, es un modelo que ha de ser definido en su integridad con la colaboración de estas Administraciones. De otro, y por esa misma razón, hace descansar la responsabilidad, ahora sin excusas, de la mejora del modelo respecto de su propio empleo público en las Comunidades Autónomas y los entes locales.

Por tanto, tras su aprobación, y corresponde fundamentalmente a las Comunidades Autónomas, era el momento de continuar la senda emprendida en esta reforma que, sin embargo con crisis y sin ella, se está demorando en demasía, si dejamos a salvo algunas Comunidades Autónomas que, como Valencia, Asturias, Castilla-La Mancha, Aragón, etc., han emprendido, en mayor o menor medida, con mayor o menor fortuna, y a mayor o menor velocidad, dicha labor ${ }^{18}$. Desgraciadamente el período de crisis no solo no ha impulsado mayores reformas, sino que, muy al contrario, o ha ralentizado las reformas emprendidas allí donde se habían iniciado, ha demorado las mismas en aquellas CCAA que no las habían emprendido y, en fin, también ha acentuado algunas disfunciones del sistema muy específicamente en el sector local donde la normativa de la crisis (la LRSAL) ha introducido más confusión que soluciones a los problemas que ya estaban planteados.

Ahora, sin embargo, es necesario retomar la senda olvidada. Ahora que las consecuencias de la crisis económica más perentorias dejan de tener un peso específico impeditivo de las mismas y que es preciso resolver, sin más demora, la construc-

18 Esta demora, inexplicable ciertamente, puede encontrar explicación, a juicio de JIMENEZ ASENSIO, R. y CASTILLO BLANCO, F.A., Informe sobre el Empleo Público Local. Balance y propuestas para su racionalización en el marco del empleo público., Fundación Democracia y Gobierno Local, Madrid, 2009, pág. 104, en dos factores: "El primero, como se ha visto, es que el EBEP es una norma compleja que hasta cierto punto supone un cambio de paradigma en el modo y manera de configurar el empleo público. Requiere un cambio de cultura de la organización, una inversión en nuevos instrumentos y herramientas de gestión, así como una potenciación y refuerzo institucional de las unidades de gestión de recursos humanos en las Administraciones Públicas. En suma, un cúmulo de retos, pero que abren asimismo no pocas oportunidades para una mejora y modernización de las vetustas estructuras y métodos de gestión de personas en nuestras organizaciones públicas.

El segundo factor, mucho más contingente (al menos eso esperamos), es la crisis económica que azota a las economías occidentales (aunque se puede afirmar que es una crisis globalizada) y, especialmente, a España. El EBEP es, y así se debe reconocer, una norma "cara" en su aplicación, sobre todo depende como se haga esta. Dicho rápidamente, poner en marcha un buen sistema de evaluación del desempeño, así como luego aplicarlo de forma óptima, requiere un gasto notable. Lo mismo se puede decir de la implantación de un sistema de carrera profesional horizontal, pues si no se hace de forma escalonada y racional el incremento de gasto puede generar puntas insostenibles que presionen sobre unos depauperados presupuestos. En menor medida, una buena dirección pública profesional requiere de alguna necesaria inversión, así como la puesta en marcha de una potente unidad de recursos humanos exige gasto". 
ción de la burocracia profesional que nuestro país, y más concretamente, Andalucía demanda. Y también, por ello, es un buen momento para tener en cuenta nuevos elementos en relación a la prestación de los servicios que, a buen seguro, deberían de ser tenidos en cuenta en el desarrollo legislativo del EBEP. Desde luego, y si el legislador autonómico no actúa, las bondades que en muchos aspectos, sin duda, tiene el EBEP permanecerán inactivas y todo el potencial modernizador que algunas de estas previsiones tienen como elemento de cambio, seguirán adormecidas. Piénsese, por ejemplo, que los grandes motores de cambio que introduce esta norma respecto del modelo hasta 2007 vigente de empleo público eran principalmente tres: a) La carrera profesional (sobre todo la implantación de la carrera horizontal), b) La evaluación del desempeño; y c) La figura del directivo público profesional. Pues bien, estos tres motores de cambio requieren, con mayor o menor intensidad, que el legislador de desarrollo del EBEP actúe y que, más concretamente, y en Andalucía que el legislador andaluz acometa de una vez por todas esa difícil aunque necesaria responsabilidad.

En cualquier caso, debe tenerse en cuenta que, en su caso, numerosas cuestiones han de ser objeto de debate en este ámbito. Desde la configuración, más funcionarial o más laboral del empleo público, hasta la racionalización de los cuerpos y escalas de funcionarios existentes y su mayor conexión con el sistema de puestos de trabajo, el desarrollo del sistema de carrera y el establecimiento de un adecuado sistema retributivo, el establecimiento de mecanismos adecuados para la distribución de efectivos, la ruptura del dogma de adscripción indistinta de los puestos de trabajo y un efectivo funcionamiento de las áreas funcionales, la afirmación y garantía de los principios constitucionales atinentes al empleo público y específicamente a su selección introduciendo nuevos elementos para asegurar una selección adecuada, etc. Elementos, entre otros muchos a los que podríamos referirnos, en los que se deberá seguir insistiendo si se quiere que ese primer paso que significó el EBEP tenga ahora, como consecuencia de la promulgación de la normativa autonómica, su efectiva plasmación en un funcionamiento más óptimo del sistema de empleo público en general y, muy particularmente, del sistema de empleo público autonómico y local.

Junto a ello, nuevas exigencias derivadas de la decidida incorporación de la mujer española al mundo del trabajo, y al sector público en particular, y las nuevas exigencias que la prestación de servicios requiere, imponen, asimismo, la implementación de nuevos desarrollos normativos que se plasmen en medidas tales como la profundización en la conciliación de la vida familiar y laboral; el establecimiento de medidas de discriminación positiva en la carrera administrativa a favor de la mujer en aquellos sectores de nuestra Administración en que las mismas no hayan alcanzado un mínimo de puestos de responsabilidad; nuevas formas de prestación de trabajo y descentralización de la prestación del mismo; la participación en la de- 
finición de objetivos de unidades orgánicas; la posibilidad de existencia de puestos de trabajo con multifunciones o polivalentes sin adscripción permanente a unidades orgánicas permanentes; una reordenación del tiempo de trabajo con potenciación del trabajo a tiempo parcial, flexible o en jornada partida; el establecimiento de jornadas complementarias en momentos punta de trabajo compensadas con días de descanso en períodos de menor intensidad laboral, un adecuado desarrollo de las situaciones administrativas que responda a los requerimientos de reestructuración de plantillas que, a buen seguro, hemos de abordar en los tiempos actuales, abordar la regulación de la desvinculación, etc., pero sin olvidar, también, la necesidad de estructurar también claramente una tabla de deberes y de exigencias éticas que materialice las previsiones en este caso recogidas en el EBEP y responda a las exigencias de servicio que el ciudadano plantea a nuestras Administraciones públicas (controles de integridad, calidad, transparencia, cartas de servicios, reestructuración de los sistema de responsabilidad, plena introducción de los sistemas de evaluación del desempeño, etc...).

Ya lo he dicho en otro sitio, pero creo que es preciso repetirlo. La respuesta a estas cuestiones debiera pasar desde luego, en primer lugar y antes de adentrarnos fervorosamente y sin suficientes criterios por el iter legislativo, en realizar necesariamente un análisis más exhaustivo de los problemas que aquejan a la función pública autonómica y al empleo público en la Administración local y universitaria de las distintas Comunidades Autónomas y, en lo que nos afecta, en Andalucía. Y en qué medida, cómo y en qué aspectos la existencia de una legislación autonómica en la materia puede ayudar a resolver éstos. Desde luego, y en la actualidad, no puede argumentarse para afrontar estos retos la inexperiencia o la falta de competencia. Ambas cuestiones han quedado definitivamente superadas tras la reforma estatutaria acontecida ya hace diez años en Andalucía, y especialmente tras la aprobación del EBEP, y solo queda el reto de abordar este objetivo con serenidad, reflexión y la suficiente visión de futuro.

Esos retos que el propio EBEP recoge quedan pendientes para su concreción de una actitud activa del legislador autonómico que vaya configurando un modelo de empleo público que, a su vez, sea también flexible y abierto en su diseño con el fin de no hipotecar las políticas de recursos humanos que otras administraciones, ya sean locales o universitarias, quieran poner en marcha. Quien se escude en que la todavía situación económica que existe aconseja no poner en marcha un proceso de reformas tal vez ignore que es precisamente en épocas de crisis económica o de desaceleración cuando realmente las administraciones públicas más necesitan adaptarse a las necesidades del momento y abordar profundos procesos de reforma. Y nótese que no hemos hecho prácticamente nada. 
La situación ahora, y tras la aprobación del EBEP y de las distintas reformas estatutarias, parece de nuevo ser singularmente distinta. Y es que una cuestión de especial trascendencia es la que se refiere a la aplicación del EBEP y la normativa de desarrollo autonómica a otras Administraciones públicas en el territorio de la Comunidad Autónoma y, más específicamente, en lo que se refiere a la Administración local y al personal de administración y servicios de las Universidades que, en este sentido, se encuentra en una situación similar ${ }^{19}$.

\section{LAS DISPOSICIONES EN MATERIA DE EMPLEO PÚBLCO CON- TENIDAS EN EL ESTATUTO DE AUTONOMÍA DE ANDALU- CÍA Y LA INCIDENCIA EN ÉSTAS DE LA JURISPRUDENGIA GONSTITUCIONAL.}

Como ya se ha apuntado someramente con anterioridad, un nuevo contexto de reformas territoriales ha orientado de forma definitiva la asunción competencial sobre este bloque normativo que, parece lógico, no podía ser ajeno al nuevo marco autonómico que tanto en lo que se refiere a las Comunidades Autónomas como a las Administraciones Locales se abre en esta etapa de reformas ${ }^{20}$, pero también, y es pre-

19 En efecto, el artículo 73.3 de la Ley Orgánica de Universidades remite a esta Ley y sus disposiciones de desarrollo, en primer término, la regulación del personal de administración y servicios de las Universidades, pero, en segundo término, establece de aplicación a éstos a la legislación de función pública. Por último, y este no es un dato menor, remite a los Estatutos de las Universidades como no podía ser de otra forma dado el principio de autonomía universitaria recogido constitucionalmente.

20 Junto a la bibliografía que se cita en el texto puede consultarse, además y entre otros, los siguientes trabajos: ALBERTÍ ROVIRA, Enoch: "El blindaje de las competencias y la reforma estatutaria" Revista catalana de Dret Públic no 31 2005; BIGLINO CAMPOS, Paloma: "Reforma de los Estatutos de Autonomía y distribución de competencias" Revista Jurídica de Castilla y León. Número Extraordinario: La Reforma de los Estatutos de Autonomía. 2004; CAAMAÑO DOMÍNGUEZ, Francisco: "Las necesidades de reforma constitucional y estatutaria del Estado autonómico" En Reformas territoriales: jornadas de Sigüenza Ed. Pablo Iglesias 2006; CANTERO MARTÍNEZ, Josefa; CANTOS CANTOS, José María; CASTELLS ARTECHE, José Manuel; CORRETJA TORRENS, Mercè; GARCÍA ROCA, Javier; GARRIDO CUENCA, Nuria; MUÑOZ MACHADO, Santiago; PAREJO ALFONSO, Luciano: "La reforma del estado autonómico" Centro de Estudios políticos y constitucionales 2005; CASCAJO CASTRO, José Luis: "Sobre la Reforma de los Estatutos de Autonomía: anotaciones de un oyente" Revista Jurídica de Castilla y León. Número Extraordinario: La Reforma de los Estatutos de Autonomía. 2004; CONTRERAS CASADO, Manuel: "Reforma estatutaria y Estado autonómico: en construcción (entre la necesidad y la oportunidad) En De la reforma estatutaria, Monografías de la Revista Aragonesa de Administración Pública, Zaragoza, 2006; DOMÍNGUEZ GARCíA, Fernando: "Los Estatutos de Autonomía de las Comunidades Autónomas: una aproximación a los principales debates doctrinales" Revista Catalana de Dret Públic no 31 2005; EMBID IRUJO, Antonio: "¿Reforma de Constitución y de Estatutos de Autonomía? Aportaciones a un debate de actualidad". Justicia administrativa: Revista de derecho administrativo $\mathrm{n}^{\circ} 22$ 2004; FERRET JAQUES, Joaquim: "Estatutos de Autonomía: función constitucional y límites materiales" Revista catalana de Dret Públic no 31 2005; SOLOZÁBAL ECHABARRÍA, Juan José: "Sobre las Reformas Estatutarias y la propuesta del Parlamento catalán" Revista Jurídica de Castilla y León. Número Ex- 
ciso subrayarlo, a una nueva consideración, a mi juicio más respetuosa con el marco constitucional, de lo que debe significar la legislación básica en esta materia, más adecuada a la evolución del empleo público en nuestro país, a la propia organización de éste, y a las propias tendencias, perfectamente identificadas en otros marcos regulatorios europeos, de profundizar en la descentralización de la toma de decisiones en esta materia.

$\mathrm{Y}$ es desde este punto de vista desde donde puede mantenerse que, al menos a mi juicio, el Estatuto Básico del Empleado Público, como una de las primeras normas básicas dictadas tras la primera oleada de reformas estatutarias, responde a este esquema, que ciertamente, se quiera o no y como hemos aludido más atrás, es un esquema que reinterpreta el alcance de la legislación básica en esta materia que, hasta este momento, había tenido como punto de referencia una visión de lo básico excesivamente amplia y excesivamente anclada en la legislación de función pública estatal hasta esos momentos vigente. Lógicamente, es en este preciso instante, a menos que intereses espurios o desidia ante la problemas nos impidan ver que el mantenimiento de la competitividad alcanzada en estos últimos años exige abordar una reforma de la Administración y del empleo público. Ahora, y con suficiente distancia, es preciso decidir lo que se debe y conviene realizar.

\section{El alcance de las previsiones contenidas en los Estatutos de Autonomía de "segunda generación": especial referencia al Estatuto de Autonomía de Andalucía y Cataluña y sus diferencias ${ }^{21}$.}

Ciertamente, y aunque el Informe de la Comisión al que ya se ha hecho referencia, se elaboró mientras se debatían las reformas de algunos Estatutos de Autonomía, y muy en particular el de Cataluña, sus conclusiones no pueden considerarse el resultado del debate acontecido en torno a éste. No es que las reformas territoriales en marcha no tuvieran su influencia, sino que más bien creo que se puede hablar de una influencia con un carril de doble dirección. Así si las propuestas de debate en dicha reforma aconsejaban unas propuestas de contenido básico que permitiesen definir políticas propias a las distintas Administraciones territoriales, no parece menos cierto que las conclusiones del Informe de la Comisión pudieran haber tenido

traordinario: La Reforma de los Estatutos de Autonomía. 2004; TRUJILLO, Gumersindo: "Escritos sobre estructura territorial del Estado" Secretaría General del Senado. Dirección de Estudios y Documentación. Departamento de Publicaciones 2006; VICIANO PASTOR, Roberto: "Constitución y reforma de los Estatutos de Autonomía" Tirant lo Blanch 2005.

21 En extenso pueden verse mis trabajos: Competencias en materia de función pública: (Comentario al art. 76.1 y 2) Comentarios al Estatuto de Autonomía para Andalucía (coord. por Santiago Muñoz Machado, Manuel Rebollo Puig), 2008, págs. 733-761 y L'Estatut bàsic de l'empleat públic: les competències autonòmiques, Revista Catalana de Derecho Público, n 45,2012 
alguna influencia en la redacción definitiva del precepto del Estatuto de Cataluña que establece las competencias de la Generalitat, exclusivas y compartidas, en materia de función pública y sobre el régimen del personal (artículo 136), sobre todo si comparamos dicho precepto con el que fue remitido en su día a las Cortes Generales desde el Parlamento de Cataluña.

Pero también es preciso subrayar, desde este momento, que el Estatuto Básico del Empleado Público, asentado en las consideraciones de la citada Comisión de Expertos, no parece que sea incompatible con las reformas estatutarias acontecidas y mucho menos tras la sentencia del tribunal constitucional dictada a propósito del Estatuto de Cataluña. Su extensión definitiva -un centenar de artículos y varias disposiciones transitorias, finales adicionales y derogatorias- no debe ocultar que dicha Ley se limita a regular, en muchos aspectos mediante normas de remisión meramente directivas, los principios ordenadores del empleo público, la adquisición y pérdida de la condición de empleado público, las situaciones administrativas y los derechos y deberes del personal al servicio de las Administraciones Públicas, incluido el régimen disciplinario, competencias éstas que la mayoría de los Estatutos aprobado reconocen como de titularidad compartida con el Estado ${ }^{22}$, como no podía ser menos en virtud del artículo 149.1.18 a de la Constitución.

De esta forma, y conforme a lo ya apuntado, la mayoría de las reformas estatutarias distinguen con distinto alcance, y no siempre con el suficiente acierto, entre

${ }_{22}$ Bien es cierto que, en el caso de Cataluña, no se hace mención alguna al régimen disciplinario o a la carrera profesional de los empleados públicos como competencia compartida a pesar de ser ésta una materia que el propio Tribuna Constitucional había fijado como de contenido básico (STC 235/1991, de 12 de diciembre y STG 1/2003). En el mismo sentido lo apuntó MORCILLO MORENO, J. ”Administración Pública y Régimen Jurídico de la Comunidad Autónoma" en AAVV, Reformas Estatutarias y Distribución de Competencias", Instituto Andaluz de Administración Pública, Sevilla, 2007 pag. 199 quien, asimismo, señalaba que, desde su punto de vista, las previsiones estatutarias de Cataluña rozan la inconstitucionalidad. Respecto del alcance de las competencias autonómicas en esta concreta materia puede consultarse AGUADO I CUDOLÁ, V., "El régimen disciplinario en el Estatuto Básico del Empleado Público: los espacios abiertos a las Comunidades Autónomas y Entes Locales", en las Actas del III Congreso de la Asociación Española de Profesores de Derecho Administrativo, publicadas por el Instituto Andaluz de Administración Pública, Sevilla, 2009. Debe tenerse en cuenta, sin embargo, que como establece la STC 31/2010, "es patente que el art. 136 b) EAC, al formalizar la competencia autonómica como compartida, presupone la plena virtualidad de la competencia normativa básica del Estado en la materia (art. 149.1.18 CE); sin que la omisión en la relación no exhaustiva que efectúa de algún aspecto esencial del régimen estatutario de los funcionarios públicos, como son la carrera administrativa y el régimen disciplinario, limite en el precepto enjuiciado la plena efectividad de la competencia estatal, pues obvio es que la carrera administrativa puede ser incluida, como ocurre con el régimen retributivo (que tampoco se cita en el precepto estatutario impugnado), entre los "derechos" de los funcionarios, mientras que el régimen disciplinario guarda relación con los "deberes" de los mismos, derechos y deberes que, efectivamente, están incluidos en la controvertida letra b). 
competencias exclusivas y compartidas en esta materia ${ }^{23}$. Lo que exige, siquiera sea brevemente, una reflexión sobre esta distinción que no aparece con la misma claridad, aunque deba ser sobreentendida, en todos los Estatutos.

Desde este punto de vista, comencemos por señalar que en materia de empleo público no hay un modelo uniforme en la forma y manera a que se hace alusión en los textos estatutarios aprobados a la asunción de las competencias en materia de empleo público, aunque al final forzosamente haya que preguntarse si, sin perjuicio de que exista una dicción diferente en los textos estatutarios, el alcance de las competencias autonómicas puede resultar realmente distinto.

De esta forma, si en la mayoría de los Estatutos aprobados ${ }^{24}$, con mayor o menor acierto en su redacción, se sigue una fórmula, establecida con una cláusula de carácter general, de considerar el empleo público sólo como una competencia compartida, en los Estatutos de Cataluña y Andalucía se opta por distinguir en esta materia entre competencias exclusivas y compartidas y constituyen, de forma clara, un punto aparte en la forma y alcance en que se asumen las competencias en materia de empleo público.

${ }_{23}$ En cualquier caso, es conveniente subrayar que, de acuerdo con la STC de...., "el Estatuto puede atribuir una competencia legislativa sobre determinada materia, pero qué haya de entenderse por "competencia" y qué potestades comprenda la legislativa frente a la competencia de ejecución son presupuestos de la definición misma del sistema en el que el Ordenamiento consiste y, por tanto, reservados a la Norma primera que lo constituye. No es otro, al cabo, el sentido profundo de la diferencia entre el poder constituyente y el constituido ya advertido en la STC 76/1983, de 5 de agosto. La descentralización del Ordenamiento encuentra un límite de principio en la necesidad de que las competencias cuya titularidad corresponde al Estado central, que pueden no ser finalmente las mismas en relación con cada una de las Comunidades Autónomas - en razón de las distintas atribuciones competenciales verificadas en los diferentes Estatutos de Autonomía-, consistan en facultades idénticas y se proyecten sobre las mismas realidades materiales allí donde efectivamente correspondan al Estado si no se quiere que éste termine reducido a la impotencia ante la necesidad de arbitrar respecto de cada Comunidad Autónoma, no sólo competencias distintas, sino también diversas maneras de ser competente".

24 En efecto, el artículo $75.13^{\circ}$ del Estatuto Aragonés establece que es una competencia compartida el régimen estatutario de los funcionarios de la Comunidad Autónoma de Aragón y de su Administración Local y las especialidades del personal laboral derivadas de la organización administrativa y la formación de este personal.). En el caso de Baleares el artículo 31.3 establece como una competencia de desarrollo legislativo y de ejecución, en el marco de la legislación básica estatal, el Estatuto de los funcionarios de la Administración de la Comunidad Autónoma y de la administración local. Aun más parco es el Estatuto de Valencia y de esta forma su artículo 50.1 establece que le corresponde el desarrollo legislativo y la ejecución, en el marco de la legislación básica, del régimen estatutario de sus funcionarios. Para el Estatuto Canario corresponde a la Comunidad Autónoma de Canarias la competencia compartida en las siguientes materias :a) El régimen jurídico de la Administración de la Comunidad Autónoma de Canarias y régimen estatutario de sus funcionarios y personal estatutario, así como de su personal laboral (artículo 49.2). Por su parte, el Estatuto Castellano-manchego, en su artículo 45, se refiere exclusivamente a su personal en el marco de la legislación básica del Estado. 
En efecto, con una dicción que comienza siendo similar pero que finalmente no es idéntica al artículo 136 del Estatuto de Cataluña, y debe decirse que mucho más respetuosa a la distribución de competencias en esta materia entre el Estado y la Comunidad Autónoma, el artículo 76 del EAA establece que corresponde a la Junta de Andalucía, en materia de función pública, respetando el principio de autonomía local ${ }^{25}$ :

“a) La competencia exclusiva sobre la planificación, organización general, la formación y la acción social de su función pública en todos los sectores materiales de prestación de los servicios públicos de la Comunidad Autónoma.

b) La competencia compartida sobre el régimen estatutario del personal al servicio de las Administraciones andaluzas.

c) La competencia exclusiva, en materia de personal laboral, sobre la adaptación a las necesidades derivadas de la organización administrativa y sobre la formación de este personal ${ }^{926}$.

25 Dicho artículo fue objeto de impugnación en sus apartados a) y b) argumentando la no alusión al régimen disciplinario y la carrera profesional y por su conexión con el artículo 111, aunque para el Tribunal Constitucional, en su sentencia 31/2010 "El art. 111 EAC no se ajusta, por tanto, al cometido de la sistematización de las categorías del régimen constitucional de distribución de competencias que, según tenemos repetido, puede desempeñar, sino que, elevando a regla esencial una sola de las variables admitidas por este Tribunal en la definición del concepto de las bases estatales, termina por definir el ámbito competencial del Estado. Si las bases son "principios" o "normación mínima" no es asunto a dilucidar en un Estatuto, sino sólo en la Constitución, vale decir: en la doctrina de este Tribunal que la interpreta. Ello es así, ante todo, por razones de concepto. Pero, además, por razones de orden estructural y práctico. De un lado, porque el concepto, el contenido y el alcance de las bases no pueden ser, como regla general, distintos para cada Comunidad Autónoma, pues en otro caso el Estado tendría que dictar uno u otro tipo de bases en función de lo dispuesto en cada Estatuto de Autonomía. De otro, porque, siendo mudables las bases (STC 1/2003, de 16 de enero), también lo es, en correspondencia inevitable, el ámbito disponible por la legislación de desarrollo, de manera que la rigidez procedimental de un Estatuto lo convierte en norma inapropiada para determinar con detalle el alcance de las potestades inherentes a esa legislación. Como consecuencia de lo anterior, es inconstitucional, y por tanto nulo, el inciso "como principios o mínimo común normativo en normas con rango de ley, excepto en los supuestos que se determinen de acuerdo con la Constitución y el presente Estatuto”. Con su supresión, el art. 111 EAC se limita a describir correctamente las facultades comprendidas en la competencia de desarrollo de unas bases estatales cuyo contenido y alcance serán siempre, y sólo, las que se desprenden de la Constitución interpretada por este Tribunal".

Entendido, de esa manera, a juicio del Tribunal Constitucional no se produce problema alguno en su conexión con el artículo 136.

26 El artículo 136 del Estatuto de Autonomía de Cataluña establece que corresponde a la Generalidad:

“a) La competencia exclusiva sobre el régimen estatutario del personal al servicio de las Administraciones públicas catalanas y sobre la ordenación y la organización de la función pública, salvo lo dispuesto en la letra b).

b) La competencia compartida para el desarrollo de los principios ordenadores del empleo público, sobre la adquisición y pérdida de la condición de funcionario, las situaciones administrativas y los derechos, deberes e incompatibilidades del personal al servicio de las Administraciones públicas.

c) La competencia exclusiva, en materia de personal laboral, para la adaptación de la relación de puestos de trabajo a las necesidades derivadas de la organización administrativa y sobre la formación de este personal”. 
Por su parte el artículo 136 EAA se refiere al necesario contenido de éste estableciendo que "La ley regulará el estatuto de los funcionarios públicos de la Administración de la Junta de Andalucía, el acceso al empleo público de acuerdo con los principios de mérito y capacidad, y establecerá un órgano administrativo de la función pública resolutorio de los recursos que se interpongan sobre esta materia"'27.

Como puede verse y refiriéndonos ahora a las competencias de la Comunidad Autónoma, bien que respetando el principio de autonomía local, la competencia exclusiva con referencia al marco que establece el artículo 149.1.18 CE es referida al personal al servicio de su función pública, a diferencia del Estatuto de Cataluña que se refiere a las Administraciones públicas catalanas ${ }^{28}$, sin perjuicio de lo establecido sobre legislación compartida en el siguiente apartado que ya si se refiere al conjunto de las Administraciones públicas de Andalucía.

Es de recordar, en cuanto al termino exclusividad, que la Sentencia del Tribunal Constitucional 31/2010, de 28 de junio, en una sentencia de las denominadas interpretativas, argumentó refiriéndose al Estatuto de Cataluña, que "los Estatutos son las normas constitucionalmente habilitadas para la asignación de competencias a las respectivas Comunidades Autónomas en el marco de la Constitución. Lo que supone, no sólo que no puedan atribuir otras competencias que no sean las que la Constitución permite que sean objeto de atribu-

$27 \mathrm{Al}$ igual que los preceptos anteriores, el texto del art. 136 EAA, referido al empleo público, tiene su origen ya en los primeros documentos de gestación de la reforma estatutaria. Así, en el primer informe de la Ponencia para la reforma del Estatuto de Autonomía, de junio de 2005, se plasma el acuerdo de los grupos políticos para incluir una referencia a la función pública del siguiente tenor: «La ley de la función pública andaluza regulará el acceso a la misma con arreglo a los principios de mérito y capacidad, así como el estatuto de los funcionarios al servicio de la Administración andaluza». Y en el posterior informe definitivo de la Ponencia, de enero de 2006, aprobado ya por mayoría, se añadió el mandato para establecer «un tribunal administrativo de la función pública resolutorio de los recursos que se interpongan sobre esta materia», texto que sería ya casi definitivo pues solo en la tramitación se sustituyó el término "tribunal” por "órgano"

${ }_{28} \quad$ El Estatuto de Cataluña pretendía un blindaje competencial frente a las intromisiones estatales a las competencias propias, y para ello se creaba ex novo un sistema rígido de delimitación y atribución de competencias basado en: a) la definición del alcance de las funciones normativas y ejecutivas que corresponde a la Generalitat -y por exclusión al Estado- para cada tipo de competencia; b) la especificación de las materias y submaterias que "en todo caso" corresponderían a la Generalitat; y c) la previsión de fórmulas de colaboración de la Generalitat con el Estado en asuntos propios de este en que resultan implicadas competencias e intereses de la Comunidad Autónoma.

La sentencia 31/2010, de entrada, da un valor descriptivo a la enumeración de las funciones que integran las competencias, reservándose para sí mismo, en tanto que Supremo intérprete de la Constitución, un papel decisivo a la hora de definirlas, por tratarse a juicio de la sentencia, de una función propiamente constitucional (FJ 58). A continuación, efectúa una interpretación conforme a la Constitución tanto de lo establecido respecto a las competencias exclusivas de la Generalitat (art. 110), como respecto a las ejecutivas (art. 112). A estos efectos, y respecto del alcance del artículo 110, dirá que “...el sentido del precepto se compadece sin dificultad con el art. 149.3 CE, cuyas cláusulas de prevalencia y supletoriedad no se ven menoscabadas por la norma en cuestión. 
ción estatutaria, sino, ante todo, que la competencia en si sólo pueda implicar las potestades que la Constitución determine. El Estatuto puede atribuir una competencia legislativa sobre determinada materia, pero qué haya de entenderse por "competencia" y qué potestades comprenda la legislativa frente a la competencia de ejecución son presupuestos de la definición misma del sistema en el que el Ordenamiento consiste y, por tanto, reservados a la Norma primera que lo constituye".

De esta forma, en el caso andaluz y a diferencia del Estatuto de Cataluña, se preserva la competencia estatal de carácter básico referida a la adquisición y pérdida de la condición de funcionario, las situaciones administrativas y los derechos, deberes e incompatibilidades y el resto de materias de competencia estatal.

\section{La significación del término competencias exclusivas en materia de empleo público ${ }^{29}$.}

Las reformas estatutarias no han contribuido sin embargo a despejar, me temo, las dudas que ya con anterioridad planteaban las declaraciones de exclusividad y que obligan, por tanto, a interpretar el alcance de éstas conforme a la Constitución (SSTC 69/1982, 20/1988, 56/1990) ${ }^{30}$.

Si para el Estatuto de Andalucía las competencias exclusivas comprenden la potestad legislativa, la potestad reglamentaria y la función ejecutiva, íntegramente y sin perjuicio de las competencias atribuidas al Estado en la Constitución ${ }^{31}$, cumpliendo en éstas la legislación estatal una función de supletoriedad (artículo 42.2.1 ${ }^{\circ}$ ), el Estatuto de Cataluña no realiza salvedad alguna - aunque así deba ser entendido- y en las mismas corresponde únicamente a la Generalitat el ejercicio de estas potestades y funciones,

${ }^{29}$ Téngase en cuenta, como apunta BALAGUER GALLEJON, F., "Competencias Exclusivas" en AAVV, Reformas Estatutarias y Distribución de Competencias", Instituto Andaluz de Administración Pública, Sevilla, 2007, p. 23, que en los Estatutos conviven dos conceptos de exclusividad: uno que responde a una concepción de plenitud de potestades y facultades sobre una materia, y, por otro lado, el de exclusividad por referencia a la competencia sobre la materia, sea cual sea el tipo de facultades que se pueden desarrollar sobre ella. Y añade (p. 29) que las previsiones autonómicas sobre exclusividad no ha ido acompañada de una precisa delimitación competencial de acuerdo con un concepto de "exclusividad" en sentido estricto por lo que será preciso una interpretación constitucional que defina, en cada caso, el alcance de ésta.

30 Las competencias exclusivas, según establece la STC 31/2010, pierden este carácter ante otras competencias estatales que incidan sobre el ámbito material, aclarando además que "para la proyección de las competencias estatales sobre la materia [no] pueda ser obstáculo el empleo de la expresión "en todo caso" por los preceptos estatutarios", para referirse a la enumeración de materias y submaterias, pues tienen una virtualidad "descriptiva" (FJ 59). Las competencias ejecutivas no incluyen la potestad reglamentaria con carácter general sino sólo los reglamentos de organización interna y de ordenación funcional de la competencia ejecutiva autonómica", además de la ejecución propiamente dicha (FJ 61).

31 Así también se salva en el Estatuto de Autonomía de Aragón (artículo 35.2) o en el de Canarias (artículo 49). 
mediante las cuales puede establecer políticas propias (artículo 110)32. De todas formas, y es preciso insistir en ello, esa competencia declarada como exclusiva no puede sino ser interpretada conforme a la Constitución por lo que, se quiera o no, la misma estará condicionada por los títulos de competencia estatal que habiliten a éste a participar en la tarea de regulación de esta materia ya que, efectivamente, y como indicó de forma oportuna MUÑOZ MACHADO, los Estatutos no son Constitución ${ }^{33}$.

Por consiguiente, y refiriéndonos en forma estricta al caso andaluz, la fórmula utilizada en Andalucía, sin perjuicio de que permita establecer políticas propias y especialmente en lo que se refiere a la ejecución de las mismas o a sectores específicos dentro de las materias de competencia compartida, no excluye la competencia estatal y es plenamente compatible con las previsiones contenidas en el Estatuto Básico del Empleado Público en virtud de las cuales el Estado ejerce su competencia en la materia referida y que, como se ha expresado, dejan un amplio campo a la legislación de desarrollo autonómica ${ }^{34}$. Y también local ${ }^{35}$.

32 La Sentencia 31/2010, dirá, en definitiva respecto de la cuestión que esa "preferencia" del Derecho autonómico en materia de competencias exclusivas de la Generalitat no impide la aplicación del Derecho del Estado emanado en virtud de sus competencias concurrentes y, por tanto, "En definitiva, el art. 110 EAC no es contrario a la Constitución en tanto que aplicable a supuestos de competencia material plena de la Comunidad Autónoma y en cuanto no impide el ejercicio de las competencias exclusivas del Estado ex art. 149.1 CE, sea cuando éstas concurren con las autonómicas sobre el mismo espacio físico u objeto jurídico, sea cuando se trate de materias de competencia compartida, cualquiera que sea la utilización de los términos "competencia exclusiva" o "competencias exclusivas" en los restantes preceptos del Estatuto, sin que tampoco la expresión "en todo caso", reiterada en el Estatuto respecto de ámbitos competenciales autonómicos, tenga otra virtualidad que la meramente descriptiva ni impida, por sí sola, el pleno y efectivo ejercicio de las competencias estatales".

33 MUÑOZ MACHADO, S., "El mito del Estatuto-Constitución y las reformas estatutarias" Informe Comunidades Autónomas 2004, Instituto de Derecho Público 2005, pág.731.

34 Puede verse, a título de ejemplo, el listado que presenta ORTEGA ALVAREZ, L., en su trabajo "La extensión de las normas básicas en el nuevo Estatuto Básico del Empleado Público" en las Actas del III Congreso de la Asociación Española de Profesores de Derecho Administrativo, publicadas por el Instituto Andaluz de Administración Pública, Sevilla, 2009, pág. 244 y ss. Asimismo, es de reseñar ALDOMÀ BUIXADÉ, JOSEP; ARROYO YANES, LUIS MIGUEL; BOLTAINA BOSCH, XAVIER; GAMINO PONS JOSEP PERE; FÉREZ FERNÁNDEZ, MANUEL; GALA DURÁN, CAROLINA; JIMÉNEZ ASENSIO, RAFAEL. El Estatuto básico del empleado público: propuestas de desarrollo legislativo por parte de las comunidades autónomas. CEMICAL, Barcelona, abril de 2008 que puede consultarse en http://cemical.diba.cat/ es/publicaciones/ficheros/EBEP_PropuestasDesarrolloLegislativo.pdf

35 De nuevo nos remitimos al trabajo de JIMENEZ ASENSIO, R. y CASTILLO BLANCO, F.A., Informe sobre el Empleo Público Local...., op. cit. 


\section{E1 ejercicio de las competencias compartidas en esta materia.}

En cuanto a las competencias compartidas, el Estatuto de Andalucía establece en su artículo $42.2 .2^{\circ}$ que éstas comprenden la potestad legislativa, la potestad reglamentaria y la función ejecutiva, en el marco de las bases que fije el Estado en normas con rango de ley, excepto en los supuestos que se determinen de acuerdo con la Constitución, añadiendo que en el ejercicio de estas competencias, la Comunidad Autónoma puede establecer políticas propias ${ }^{36}$.

Nótese, sin embargo, respecto de éstas que el elemento principal recogido, y que creo es el verdadero sentido de las reformas sobre todo en lo que se refiere a la materia que abordamos, es que la existencia de una legislación compartida no puede, según el texto de estos Estatutos, anular la posibilidad de una política propia y singular respecto de cada uno de los bloques normativos de competencia compartida. Lo que, desde luego, implica una concepción materialmente distinta del papel de la legislación básica que, por ello, habrá de operar, ahora si, como un mínimo común denominador y con una función netamente directiva en cuanto a dar cumplimiento a los principios y valores constitucionales que inspiran una determinada materia, pero cuyo ejercicio en ningún caso puede ser excluyente de la definición que de la citada materia se realice en el ámbito autonómico ${ }^{37}$. Cuestión a la que desde luego responde,

$36 \quad$ Muchas más dudas suscita el Estatuto de Cataluña. De esta forma, el Estatuto de Cataluña establece que en las materias que el Estatuto atribuye la competencia a la Generalitat de forma compartida con el Estado, corresponden a la Generalitat la potestad legislativa, la potestad reglamentaria y la función ejecutiva, en el marco de las bases que fije el Estado como principios o mínimo común normativo en normas con rango de ley, excepto en los supuestos que se determinen de acuerdo con la Constitución y el presente Estatuto (artículo 111), añadiendo que en el ejercicio de estas competencias, la Generalitat puede establecer políticas propias, y que en estos supuestos el Parlamento debe desarrollar y concretar mediante una ley esas previsiones básicas. De esta forma, la STC 31/2010 "el precepto no se atiene estrictamente al concepto constitucional de las bases estatales, toda vez que las reduce a los "principios o mínimo común normativo" fijados por el Estado "en normas con rango de ley", cuando es lo cierto que, conforme a nuestra jurisprudencia, siendo aquél el contenido que mejor se acomoda a la función estructural y homogeneizadora de las bases y ésta la forma normativa que, por razones de estabilidad y certeza, le resulta más adecuada (por todas, STC 69/1988, de 19 de abril), no lo es menos que también es posible predicar el carácter básico de normas reglamentarias y de actos de ejecución del Estado (STC 235/1999, de 16 de diciembre), y son factibles en las bases un alcance diferente en función del subsector de la materia sobre la que se proyecten e incluso sobre el territorio (SSTC 50/1990, de 6 de abril y 147/1991, de 4 de julio, respectivamente).

37 Cuestión aparte es, desde luego, la reformulación del papel que ha de desempeñar la legislación básica respecto del ejercicio competencial autonómico y donde la tramitación del Estatuto de Autonomía de Cataluña ha reflejado la reconducción del entendimiento de éstas como simple normas directivas, sin ninguna función adicional, a una comprensión de las mismas más cercana, sin perjuicio de la crítica que merezca la abusiva utilización de las bases realizada hasta el momento en algunos sectores, a lo que hasta este momento era entendido como legislación básica. Es muy oportuna la lectura, en este punto, de ORTEGA ALVAREZ, L., "Competencias Compartidas: Bases-Desarrollo" en AAVV, Reformas Estatutarias y Distribución de Competencias”, Instituto Andaluz de Administración Pública, Sevilla, 2007, pp 43 a 50 
como hemos expuesto, el Estatuto Básico del Empleado Público que, sin perjuicio de definir contenidos mínimos, es una norma que deja abierta una amplia gama de posibilidades para la estructuración de la función pública autonómica, sin renunciar por ello a esa función directiva de las reformas que se pretenden emprender en el empleo público.

La diferencia neta entre el texto catalán y el andaluz (igualmente respecto del de Aragón) es la previsión establecida en el texto catalán en que se indica cómo se han de hacer las bases lo que no parece ser función del estatuyente sino del constituyente (con carácter principial, normativo o directivo), bien es cierto que, no está de más reiterarlo, aunque dicho precepto podría admitir su interpretación conforme a la Constitución, según ha expuesto algún sector doctrinal ${ }^{38}$, no parece que esa haya sido la interpretación que la STC 31/2010 ha dado a este precepto que, como se sabe, fue en su momento anulado ${ }^{39}$.

En cualquier caso, conviene subrayar, como ha destacado ORTEGA ALVAREZ, que las previsiones estatutarias contenidas sobre el alcance del significado de lo que significa una competencia compartida, y por consiguiente, hasta donde alcanza lo que puede ser considerado como básico, no sería aplicable a la doctrina constitucional construida sobre criterios interpretativos que sólo han tenido en cuenta el dictado de la Constitución y no la legislación vigente en ese momento ${ }^{40}$.

38 Es decir, cabe como se ha apuntado por algún sector doctrinal mantener que estamos ante una norma programática, que pretende trasladar al Estatuto la propia doctrina asentada por el Tribunal Constitucional y que, por ello, puede resultar innecesaria (juicio de oportunidad) pero no inconstitucional. Véase MONTILLA MARTOS, J.A., "La legislación básica....", op. cit., pág. 124

39 En relación con las competencias compartidas, el Tribunal Constitucional, en su STC 31/2010, declara inconstitucional el inciso relativo a los aspectos que debe considerar básicos y al rango normativo que han de tener las bases estatales: esto es, entendidas "como principios o mínimo común normativo en normas con rango de ley..." (art. 111). Para la sentencia dicho inciso "termina por definir el ámbito competencial del Estado". Asimismo la inserción de una cláusula como la citada en el Estatuto introduce una "rigidez procedimental" a lo que es un criterio jurisprudencial que el Tribunal no ha de poder modular en cada caso, pues es a dicho órgano a quien corresponde concretar en exclusiva el alcance de las bases estatales, a partir de la Constitución (FJ 60). A la vista de lo indicado, el Tribunal sigue sustancialmente la doctrina que había elaborado con anterioridad en relación con los diferentes tipos de competencias, sin perjuicio de dejar claro el papel revisor que a éste corresponde.

40 ORTEGA ALVAREZ, L., "Competencias Compartidas: op. cit., p. 39. Asimismo, y con una opinión distinta a MONTILLA MARTOS, este autor entiende que la previsión estatutaria contenida en el artículo 111 del Estatuto de Autonomía para Cataluña "modifica los efectos de toda la actual legislación básica del Estado, ya que sólo vinculan al legislador en cuanto principios, objetivos o estándares mínimos" en ORTEGA. L., SOLOZABAL, J.J., ARBOS, X., op. cit. Pág. 23. 


\section{V. ¿ES PREGISA UNA LEY DE EMPLEO PÚBLICO PARA TODAS LAS ADMINISTRACIONES DE UNA COMUNIDAD AUTÓNOMA? .}

Como es conocido, y ya se ha hecho alguna referencia, la legislación de empleo público de las Comunidades Autónomas no tenía porqué incidir exclusivamente en su propio personal. Efectivamente, MORELL OCAÑA ya señaló con anterioridad a estas reformas estatutarias, refiriéndose al título competencial estatal, que "es este último título habilitante de mayor extensión constituyendo una de sus manifestaciones específicas lo relativo al régimen básico de los funcionarios de las Administraciones Locales ${ }^{\prime \prime 1}$. Conclusión que, por tanto, conlleva también su desarrollo por parte de las Comunidades Autónomas respecto de los funcionarios de estas Administraciones, no solo que también en la medida en que la mayoría de las mismas han asumido competencias específicas y de desarrollo en materia de régimen local, sino más decisivo aún por las propias competencias en materia de desarrollo legislativo de las bases estatales en materia de función pública que tienen éstas.

Lo cierto y hasta ahora, sin embargo, es que un simple repaso de la legislación de las Comunidades Autónomas mostraba que dicho aspecto no era uniforme y así, junto a normas autonómicas como la dictada en su momento en Castilla-La Mancha u otras que declaraban su aplicabilidad al personal al servicio de las entidades locales de su territorio, en otros supuestos como el caso de Andalucía, aún no actualizada ni adaptada a las previsiones de la nueva legislación básica estatal, la ambigüedad de la normativa planteaba, y sigue planteando todo hay que decirlo, serias dudas sobre si resulta de aplicación al personal al servicio de los Gobiernos locales de su territorio ${ }^{42}$.

41 L. MORELL OCAÑA, "Las fuentes del Derecho Local. Problemas generales. Competencias del Estado y de las Comunidades Autónomas", REALA, n 235-236, año 1.987, pág. 524.

42 Efectivamente, y para el caso andaluz, la legislación aplicable es la establecida en el ordenamiento jurídico estatal y no en el autonómico ya que ésta no ha hecho uso de esa capacidad normativa de desarrollo de las bases establecidas por el Estado en el caso de los funcionarios locales a la que aludíamos anteriormente. En efecto, la propia Ley de Función Pública de Andalucía, amén de no incluir a los funcionarios locales en su ámbito de aplicación (artículos 1 y 3), remite expresamente (disposición adicional primera) la regulación de los funcionarios locales al servicio de las Corporaciones locales de Andalucía a una futura Ley, que no fue dictada, en la que se establezcan las disposiciones y competencias que se aplican respecto de los mismos, salvo en el caso de los funcionarios locales integrados en la función pública autonómica en que sí será de aplicación las disposiciones de dicha Ley (artículo 18) o cuando pasen a desempeñar puestos de trabajo en dicha Administración y mientras permanezcan en la misma (artículo 25.4.a); casos, estos últimos, que no se corresponden con el supuesto presente que ocupan puestos de trabajo en una organismo autónomo local y no se han integrado, por tanto, en la función pública de la Junta de Andalucía.

Por tanto, puede concluirse que excluidos de la aplicación de dicha Ley (disposición adicional primera) la legislación aplicable a éstos será la estatal de desarrollo de las bases establecidas por éste y aplicables a toda la función pública como legislación supletoria y de cierre del sistema legal según las disposiciones constitucionales y legales (art. 149.3 CE, 90.2 y 92.1 de la Ley 7/1985, de 2 de abril). 
Sin embargo, y a mi juicio, la situación ahora, y tras la aprobación del EBEP y de las distintas reformas estatutarias, parece de nuevo ser singularmente distinta. Y es que una cuestión de especial trascendencia es la que se refiere a la aplicación del EBEP y la normativa de desarrollo autonómica a otras Administraciones públicas en el territorio de la Comunidad Autónoma y, más específicamente, en lo que se refiere a la Administración local y al personal de administración y servicios de las Universidades que, en este sentido, se encuentra en una situación similar ${ }^{43}$.

Desde luego, no parece que pueda ponerse en duda la trascendencia que ello tiene respecto de la Administración local. Y no sólo por el número e importancia de éstas -su personal constituye ya aproximadamente la cuarta parte del total de los empleados públicos del país-, sino porque al carecer de potestad legislativa, las leyes de función pública local se aprueban por el Estado o las Comunidades Autónomas y, ciertamente, no siempre han tenido como referencia las características singulares que concurren en empleo público en el ámbito local ${ }^{44}$.

Una nueva norma en materia de empleo público no parece que debiera dictarse sin atender específicamente las problemáticas singulares de estos colectivos y, más allá de ello, ser dictada con la intención de dar respuesta a diversos puntos, a saber: de un lado, delimitar aquellos aspectos que deben ser comunes al personal de las Administraciones públicas en el ámbito autonómico correspondiente y, por tanto, posibilitar un cierto equilibrio, que no necesariamente uniformidad, entre los distintos colectivos en relación a las condiciones de trabajo, en términos de equidad externa e interna, con independencia de su adscripción a una u otra Administración pública; de otro, y en forma complementaria al anterior, determinar en qué aspectos la norma autonómica ha de asumir un papel meramente directivo dejando a estas Administraciones la posibilidad de optar entre diversas soluciones o, simplemente, establecer su propio sistema en el marco de la norma autonómica haciendo efectivo

43 En efecto, el artículo 73.3 de la Ley Orgánica de Universidades remite a esta Ley y sus disposiciones de desarrollo, en primer término, la regulación del personal de administración y servicios de las Universidades, pero, en segundo término, establece de aplicación a éstos a la legislación de función pública. Por último, y este no es un dato menor, remite a los Estatutos de las Universidades como no podía ser de otra forma dado el principio de autonomía universitaria recogido constitucionalmente.

44 De ahí que el Informe de la Comisión al que ya se ha hecho referencia recomendara que las peculiaridades del empleo público en la Administración local se tuvieran en cuenta en la elaboración del Estatuto Básico; ciertamente, aplicando en este ámbito el mismo régimen de garantías de cumplimiento de los principios de igualdad, mérito y capacidad en el acceso y de imparcialidad en el ejercicio de las funciones públicas y reconociendo los mismos derechos y deberes básicos a los empleados públicos locales que a los demás, pero contemplando también caso por caso sus problemas específicos.

Como indica SANCHEZ MORON, M., Comentarios a la Ley del Estatuto Básico..., op. cit, pág. 69 "En realidad, el legislador ha atendido estas recomendaciones sólo en parte, pues muy pocos de los preceptos del EBEP introducen normas especiales para la Administración local. Apenas algunas en materia de negociación colectiva y la Disposición adicional segunda”. 
el principio de autonomía universitaria y local ${ }^{45}$; también, y a mi juicio de forma no menos relevante, será el tratamiento que esta norma haya de dar a la solución de problemas seculares en el ámbito de esas burocracias públicas a través de la articulación de instrumentos de cooperación y coordinación que sean efectivos y permitan superar problemas derivados de una insuficiente capacidad de gestión de los distintos subsistemas del empleo público; ofrecer respuestas a los tránsitos de personal entre las distintas Administraciones públicas y de éstas con entes descentralizados y respecto de agrupaciones de entes públicos; por último, y asimismo, dicha norma estará llamada a establecer y desarrollar, también de forma equilibrada, un sistema de movilidad interadministrativa en el marco del empleo público autonómico.

\section{Las materias de desarrollo legislativo por parte de la Comunidades Autónomas.}

Producto de la técnica legislativa adoptada por el EBEP, y que se aparta a mi juicio correctamente por lo que de clarificador tiene, de incluir en un solo texto legal la legislación básica y la legislación de desarrollo del Estado con lo que queda perfectamente definido su papel de legislador ordinario y de legislador de las bases aplicables a todas las Administraciones públicas, son las referencias que se contienen a la legislación de desarrollo en el mismo.

De esta forma, y en lo que se refiere a los funcionarios públicos de la AGE, la legislación de desarrollo habrá de ser aprobada por las Cortes Generales en caso de que revistan forma de ley y por los órganos que tienen atribuida la potestad reglamentaria cuando se trate de este supuesto. Asimismo, y en el caso de las Comunidades Autónomas, y atendiendo a las competencias asumidas en el EBEP y en sus respectivos Estatutos de Autonomía (doble criterio de deferencia), se reproduce el mismo esquema en el ámbito autonómico (artículo 6 EBEP) ${ }^{46}$. Las Entidades locales,

45 A este punto se ha referido SANCHEZ MORON Comentarios a la Ley del Estatuto Básico..., op. cit, pág. 70 precisando como el EBEP también abre un espacio normativo a las entidades locales. En opinión de dicho autor "Ahora bien, la legislación de las Comunidades Autónomas, como la del Estado, debe respetar en todo caso la autonomía local. Sucede, sin embargo, que éste es un límite impreciso (SSTC 31/1981, 27/1987, 214/1989, 109/1998, 159/2001, 51/2004, 252/2005, etc.), que el texto del EBEP contribuye muy poco a perfilar o a concretar en materia de función pública. Por consiguiente, en el marco de la legislación básica del Estado sobre función pública local, de la que forma parte el EBEP, se abre un margen importante para que las Comunidades Autónomas con competencia para ello puedan regular el régimen de la función pública local. $Y$, desde luego, podrán hacerlo siempre que exista una reserva de ley o cuando el propio EBEP se remite a lo que dispongan las leyes de función pública aplicables a cada Comunidad Autónoma y el Estado no establezca nueva legislación básica sobre la función pública local o no mantenga las normas legales vigentes. Por el contrario, en aquellos preceptos en que el EBEP apodera a cada Administración Pública o a los Gobiernos respectivos para desarrollar y aplicar su regulación, puede entenderse, salvo excepción justificada en la propia literalidad del precepto, que confiere una facultad de decisión autónoma también a las Entidades Locales sobre su propio sistema de empleo público".

46 Aunque ciertamente el artículo 6 EBEP no se refiera a normas reglamentarias y sólo aluda a las leyes sobre función pública. 
careciendo de potestad legislativa, sin embargo podrán utilizar su potestad reglamentaria para desarrollar la legislación estatal o autonómica que les sea aplicable.

De esa forma, el EBEP prevé claramente diversas materias en que la legislación de las CCAA cumple un especial papel: de entrada, y ya hemos hecho mención a ello, el sistema de carrera y las retribuciones complementarias de los funcionarios públicos. No obstante, preciso es advertir que algunas de las normas de desarrollo del EBEP en materia de función pública serán el resultado de los acuerdos que se alcancen en la negociación colectiva. Incluso ciertos acuerdos pueden tener una eficacia normativa directa, conforme al artículo 38.3 del EBEP.

Pero no sólo en aquellos aspectos diferidos en su entrada en vigor hasta el dictado de la legislación de desarrollo cumple esta normativa de desarrollo un papel relevante. Múltiples ámbitos ya se trate del personal directivo ${ }^{47}$, del régimen de situaciones administrativas, régimen disciplinario y otros variados aspectos contemplados en el EBEP quedan a la espera de la respectiva norma autonómica. De entrada, y por subrayar algunos de los más relevantes, la nueva legislación autonómica deberá pronunciarse sobre extremos tales como: a) la estructura de su personal, preferentemente laboral o funcionarial o mixto, que diseña para su modelo de empleo público con los límites establecidos en el artículo 9 EBEP; b) carrera o modelos de carrera-ya que no necesariamente ha de ser uniforme para todo el empleo público- que establece para su sistema de empleo público; c) retribuciones complementarias de los funcionarios públicos que no queda ceñido a los conceptos establecidos en el artículo 24 ni obliga a establecer un único modelo para la totalidad del personal a su servicio; d) establecimiento de un proceso selectivo propio, que respetando lo establecido en el EBEP, podrá incluir fases de reclutamiento, establecimiento de pruebas alternativas, etc. y si se exime o no del requisito de la nacionalidad para acceder a determinados empleos públicos lo que puede resultar especialmente de interés en los Gobiernos locales; e) medidas para la planificación y ordenación del empleo público; f) estructuración en Cuerpos o Escalas o, alternativamente, mediante otros sistemas de agrupación; g) establecimiento de otros sistemas de provisión de puestos de trabajo junto al concurso y la libre designación; h) medidas de movilidad entre las Administraciones públicas de Andalucía; i) desarrollo del sistema de situaciones administrativas, creación de otras situaciones administrativas no previstas en el EBEP, etc.: j) definición de las infracciones graves y leves y si se añaden o no nuevos tipos a las muy graves, estableciendo, asimismo, los elementos fundamentales de procedimiento disciplinario, etc.

47 Bien que dicha materia no ha quedado, finalmente, reservada a la Ley lo que no parece una buena opción como ha puesto de relieve SANCHEZ MORON, M Comentarios a la Ley del Estatuto Básico..., op. cit, págs. 103 y ss. 
Pero, asimismo y como ya se ha apuntado, otras cuestiones han de ser enfrentadas en materia de empleo público local. Cuestiones que tienen que ver con la estructura y organización de las entidades locales, la dirección pública, los funcionarios con habilitación de carácter estatal, etc. que también encuentran en la legislación autonómica su debida inserción, pero, en estos concretos casos, no en la legislación de empleo público sino en la legislación de régimen local dictada que desafortunadamente, y en lo que respecta a Andalucía, no ha sido especialmente afortunada ${ }^{48}$.

Como puede verse con el EBEP se abrió un espacio normativo importante, que desde luego permite la definición de un modelo propio de empleo público y el establecimiento de políticas de empleo en el sector público que atiendan a la organización propia de las Administraciones públicas de cada Comunidad Autónoma, y, en definitiva, que al fin y al cabo es lo que nos deberían en último término importar, que ayuden a resolver los muchos problemas que aquejan a las burocracias de las Administraciones públicas de un grupo importante de Comunidades Autónomas. Lo relevante, creo que es preciso volver a señalarlo, será, junto a que todas estas cuestiones respondan a un modelo concreto de estructuración y funcionamiento del empleo público, que se aminoren los déficits existentes respecto de la capacidad de gestión de los recursos humanos en algunos sectores del empleo público. Y esto implicará necesariamente decidir en cada aspecto concreto y con qué alcance dicha norma será aplicable a otras Administraciones, como se integran los distintos sistemas de empleo público, y en qué medida dicha norma habrá de habilitar un espacio propio de definición de las singularidades atinentes a su propio modelo a éstas.

\section{Las competencias en materia de personal laboral.}

Tanto el Estatuto de Cataluña en su artículo 136, como el Estatuto de Andalucía en su artículo 76, se refieren al personal laboral al servicio de las Administraciones públicas. Y en este punto es necesario precisar el alcance de dichas previsiones.

El apartado 3 del artículo 76 del Estatuto de Autonomía para Andalucía se refiere específicamente al personal laboral. En este caso, utilizando también la técnica de la competencia exclusiva bien que, en este supuesto y como no puede ser de otra forma dadas las competencias que en esta materia tiene el Estado ex artículo 149.1.7 CE, referida a dos aspectos concretos y de menor alcance: la adaptación a las necesidades derivadas de la organización administrativa y la formación de este personal. Por su parte, ya lo mencionamos, el Estatuto de Cataluña habla de la competencia exclusiva, en materia de

48 Puede verse el estudio que realizo, a propósito de Andalucía, en El empleo público en la Ley de Autonomía Local de Andalucía, Derecho local de Andalucía : la Ley 5/2010, de 11 de Junio de Autonomía Local de Andalucía / coord. por Encarnación Montoya Martín, Severiano Fernández Ramos; José Luis Rivero Ysern (dir.), 2012, págs.463-508 
personal laboral, para la adaptación de la relación de puestos de trabajo a las necesidades derivadas de la organización administrativa y sobre la formación de este personal.

De nuevo nos encontramos aquí con unas normas de compleja compresión que no aclaran muy bien que se quiere decir con "adaptación a las necesidades derivadas de la organización administrativa" ya que no parece que pueda alcanzar a aspectos normativos de reserva al Estado constitucionalmente o que preceptivamente han de desarrollarse en el marco de la negociación colectiva. De esta forma, la interpretación que haya de darse a dicha previsión más bien parece debe ser referida a aspectos de ejecución derivados de instrumentos organizativos utilizados en la estructuración del empleo público ${ }^{49}$.

$Y$ es que el EBEP como ya se sabe, y con independencia del juicio crítico que nos merezca la regulación finalmente establecida respecto del personal laboral, aúna en su texto dos tipos de regulaciones que se amparan, sin embargo, en dos títulos competencialmente distintos. Por un lado, la legislación básica aplicable a los funcionarios públicos incluidos en el ámbito de aplicación del Estatuto Básico en virtud del artículo 149.1.18, pero también y en ciertos aspectos, según lo recomendado por la Comisión constituida a tales efectos a la que ya se ha hecho referencia, al personal laboral al servicio de las Administraciones Públicas. Estas últimas normas a las que nos hemos referido, no debe olvidarse, forman parte stricto sensus de la legislación laboral y, por ellos, el título competencial de invocación no es aquí el artículo 149.1.18, sino el artículo 149.1.7, que es precisamente el que se invoca en la Disposición final primera de la Ley precisando que el EBEP se aprueba bajo la cobertura de ese título competencial "por lo que se refiere a la legislación laboral".

El Informe de la Comisión, que partía en su análisis de la dualidad de regímenes jurídicos de empleo público existente en nuestro país, y que, como es sabido, no era contraria al texto constitucional apuntó, y justificó también ha de añadirse, la necesidad de elaborar un Estatuto Básico para todos los empleados públicos, ya se tratase de personal laboral o estatutario. Lo que, por otra parte, tampoco puede calificarse de absoluta novedad y si no repárese en la tendencia creciente, en numerosas normas de rango legal y acuerdos colectivos, de unificar el régimen jurídico aplicable a ambos colectivos, sin hacer, por ello, desaparecer la singularidad de cada relación

49 De otro lado, la explicación a la dicción utilizada en el Estatuto de Andalucía quizás pueda residir en que el apartado tiene claramente un antecedente en el apartado tercero del artículo 136 del Estatuto de Autonomía de Cataluña, si bien éste, con mayor precisión, aclara que dicha adaptación es referida a las relaciones de puestos de trabajo. Y posiblemente en la intención, no declarada, de no transcribir literalmente la letra de dicho Estatuto. Esperemos, sin embargo, que el legislador autonómico llamado a desarrollar el precepto muestre, sin embargo, una mayor imaginación, con respecto al sistema de fuentes constitucionalmente establecido, en este punto. 
de empleo público (prevención de riesgos laborales, conciliación de la vida familiar y laboral, incompatibilidades, etc...).

Pero esto no significa que, desde luego, la técnica empleada por el EBEP no deba ser calificada de novedosa y, desde luego, de mayor alcance que la utilizada hasta el momento en la legislación de empleo público ${ }^{50}$, con independencia del éxito del resultado final que, como ya se ha expresado, es más discutible.

Y de esta forma, y a lo largo de su articulado, los preceptos del EBEP desde este punto de vista pueden clasificarse en diversas categorías: una primera, de carácter común cuando se refiere a los empleados públicos en general, y que, por ello, ha de entenderse referida a funcionarios públicos y personal laboral; una segunda, de carácter exclusivo para los funcionarios públicos; y, por último, una última categoría, que establecería normas solamente referidas al personal sujeto al régimen laboral. En cuanto a los preceptos de carácter común cabe referirse de forma principal a los derechos y deberes de los funcionarios públicos, a salvo de la inamovilidad característica de los funcionarios públicos, y que quedan prácticamente unificados si salvamos algunos aspectos, también numerosas normas referidas al acceso reciben igual tratamiento, como lo relativo al régimen disciplinario y otros aspectos referidos a la negociación, la ordenación de la actividad profesional, etc.

Ciertamente, es discutible, ya se ha dicho y preciso es reconocerlo, si se ha acertado o no en el alcance finalmente establecido de estas normas comunes, de menor alcance en todo caso que el sugerido por la Comisión, pero lo cierto es que el EBEP

50 Como señala SANCHEZ MORÓN, M. Comentarios a la Ley del Estatuto Básico..., op. cit, pág. 45 "Hasta ahora, la legislación general de la función pública se limitaba a reconocer la posibilidad de contratación de personal por las Administraciones Públicas "de acuerdo con la legislación laboral" (art. 7 LFCE), y a determinar qué funciones o puestos de trabajo podían ser desempeñados en ellas por personal laboral [art. 15.1.c) LMRFP, art. 92.2 LBRL y leyes de función pública de las Comunidades Autónomas, aparte de las normas legales referidas a organismos y entes públicos]. También, ciertamente, la legislación de función posterior a la Constitución, desmintiendo que la legislación laboral común fuera "plenamente aplicable" al personal laboral de las Administraciones Públicas, como pretendía el artículo 7.1 LFCE, fue incluyendo algunas reglas específicas para este personal. Así, la necesidad de seleccionarlo de acuerdo con la oferta de empleo público, mediante convocatoria pública y procedimientos que garanticen los principios de igualdad, mérito y capacidad, y el de publicidad (art. 19.1 LMRFP y legislación concordante), o su sometimiento a los planes de empleo de las Administraciones Públicas (art. 18 LMRFP). Por otra parte, algunas leyes especiales en materia de función pública extendieron también su ámbito de aplicación al personal laboral de las Administraciones Públicas o del sector público. El ejemplo más señalado es el de la Ley 53/1984, de 26 de diciembre, de Incompatibilidades del Personal al Servicio de las Administraciones Públicas, Ley, por cierto, que sigue en vigor tras la aprobación del Estatuto Básico. Pero nunca se había aprobado una Ley que, de manera tendencialmente completa, regulara tanto las normas aplicables al personal funcionario como las peculiares del personal laboral al servicio de la Administración, esto es, las que definen lo que podemos denominar una relación laboral especial de empleo público". 
constituye un primer paso en la buena dirección de dotar de mayor cohesión y homogeneidad, en lo que es preciso, en el régimen del empleo público.

Por tanto, y en suma, por lo que se refiere al personal laboral al servicio de las Administraciones públicas la normativa de desarrollo no podrá encontrarse en la legislación de las Comunidades Autónomas, sino en la legislación laboral ordinaria del Estado. Ya se trate de la legislación laboral general, y muy especialmente el Estatuto de los Trabajadores, como en las normas establecidas en los correspondientes convenios colectivos (artículo 7 EBEP).

Y si admitimos la conclusión anterior, las leyes sobre función pública que dicten las Comunidades Autónomas no podrán regular en sí mismas la relación laboral que es una materia claramente reservada al Estado, pero si que podrán establecer normas o referirse a aspectos no sustantivos o no propios de la relación laboral de empleo público ${ }^{51}$. Y, de esta forma, sólo a través de la negociación colectiva con los representantes de sus empleados podrán las Comunidades Autónomas (y las Entidades Locales) participar en la adopción de normas (convencionales) que desarrollen el Estatuto Básico para el personal laboral ${ }^{52}$.

51 Como resalta SANCHEZ MORON M. Comentarios a la Ley del Estatuto Básico..., op. cit, pág. 50. "Tal es el caso de algunas normas de procedimiento, de organización y de competencia. Algunas, como ya sucede en la actualidad, regularán aspectos previos a la relación laboral en sentido estricto. Es el caso de las que disciplinan el procedimiento de selección, que culmina con un acto administrativo separable y previo al contrato de trabajo. Otras regularán instrumentos de ordenación del empleo público, de naturaleza orgánica, como, por ejemplo, los planes de empleo público, la oferta de empleo público, los Registros de Personal o las Relaciones de Puestos de Trabajo o instrumentos similares. Otras normas, en fin, las presupuestarias, podrán establecer limitaciones a los incrementos retributivos o fijarán directamente las cuantías globales del gasto de personal. Pero en todos estos casos, no se trata de legislación laboral en sentido propio, aunque afecte a quienes tienen (o pretendan firmar) un contrato de trabajo con una Administración o ente público. De la misma manera que no son legislación laboral (ni administrativa) los preceptos del Código Penal que regulan los delitos de los funcionarios públicos, en el amplio sentido que esta expresión tiene en el Derecho penal, comprensiva de todo aquel que por disposición de la Ley, por elección o por nombramiento participe en el ejercicio de funciones públicas (art. 24.2 CP)".

52 Bien es cierto que hay que anotar que, en el ámbito universitario y tras la remisión que se hizo por la LOU, se abrió un amplio campo para la legislación universitaria no sin crítica de la doctrina por entender que se vulneraba la competencia estatal y el ámbito natural de la negociación colectiva. Véase respecto de este punto BAYLOS GRAU, A., El personal docente e investigador contratado en régimen laboral después de la reforma de la LOU en 2007, Revista de Derecho Social, nº 44, 2009 


\section{VI. ¿PORQUÉ AHORA?: EL DEBATE POR LA CONSTRUGGION DE UN MODELO DE EMPLEO PUBLICO EN ANDALUCÍA.}

\section{Es ahora el momento de modernizar nuestro empleo público.}

La función pública de Andalucía constituye un importante colectivo. Sólo si atendemos al personal directamente dependiente de ésta, ignorando al personal al servicio de los Gobiernos locales de Andalucía, Universidades y otras Administraciones públicas no territoriales, sabemos que el mismo constituye el 9 por ciento del número total de personas que trabajan en las Administraciones españolas y del 9’66 por ciento del número de personas ocupadas para el mismo ejercicio en el mercado laboral andaluz. Una cifra superior a los doscientos mil empleados públicos (cuando se incluye al personal docente y sanitario) que supone aproximadamente el treinta y cinco por ciento del gasto comprometido en los Presupuestos de la Comunidad Autónoma de Andalucía y aproximadamente el 50 por ciento del total del empleo público en Andalucía. Un funcionamiento adecuado de ésta, por tanto, y a la vista de tales cifras, no resulta una cuestión menor para nuestra Comunidad Autónoma ya que, al fin y al cabo, la efectividad del ejercicio competencial que se realice y la eficacia de los servicios prestados va a depender, en gran medida, de su adecuada estructuración, profesionalización y motivación.

Como se ha puesto de relieve en algunos Informes realizados en los últimos años en el marco de una Europa integrada los Estados que respondan con mayor diligencia y eficacia a la efectiva implementación de la normativa comunitaria serán aquellos que atesorarán una mayor fiabilidad y ofrecerán mayores certezas en los intercambios internacionales. Y es ahora, siguen razonando los Informes citados, tras la integración económica y monetaria -realizada en una época de buena coyuntura económica-, cuando el déficit de renovación de nuestras Administraciones empezará a pasar factura.

Si efectivamente, y como se reconoce con carácter general, nuestro país ha sufrido importantes cambios en las últimas cuatro décadas, dichas transformaciones no se han traducido suficientemente en las formas de operar de nuestras instituciones públicas que no han experimentado similar transformación. Cambios, por otra parte, que no se reducen a transformar ventanillas en espacios abiertos al ciudadano, a cambiar los manguitos por tarjetas de identificación o a implementar una administración electrónica, sino que seguramente exigen, y dado el volumen de PIB que gestionan, en desempeñar una función de dirección estratégica respecto de ese volumen de gasto y de gestión de los recursos que tienen las mismas. En definitiva que sepan dar una respuesta, con todas las garantías de control y transparencia democráticas exigibles, a los problemas colectivos que acechan a la sociedad en su conjunto. 
De esta forma, ya desde esa época, se incrementaron progresivamente las voces que reclamaban un cambio en las formas y en los medios para gestionar el sector público. La modernización del sector público ha sido un tema recurrente en los países de nuestro entorno desde la década de los ochenta. Procesos de mejoramiento de la atención al usuario y del reconocimiento de una esfera de derechos en sus relaciones con la Administración pública, implementación de cartas de servicios e introducción de políticas de calidad, acciones de simplificación y descentralización administrativa, desarrollo institucional y gestión pública social, limitaciones fiscales al crecimiento del sector público junto al crecimiento de la demanda de servicios propia de una sociedad de bienestar, son procesos, todos ellos, que han ido acompañando la necesidad de un sector público que racionaliza sus recursos y que ha de optimizar sus resultados a fin de constituirse, más que en una rémora, en esa infraestructura imprescindible que proporciona credibilidad y seguridad en el cumplimiento de sus compromisos de servicio a la sociedad en su conjunto y a cada uno de los ciudadanos para mantener la capacidad de supervivencia y competitividad del país en el mundo globalizado e interdependiente en el que nos movemos.

Además, todo ello, se ha producido en un entorno y cultura administrativa, según se indica en todos los Informes realizados al respecto, poco propicia a valorar y cuantificar lo público como algo propio, pero que en cambio se siente profundamente estatista dada la tradición autoritaria del país. España, y más específicamente en lo que importa Andalucía, sigue siendo un país profundamente dependiente de sus Administraciones y ello avala, si cabe con más intensidad, que las reflexiones anteriores adquieran un matiz tanto más radical en nuestro caso.

Este cambio de perspectiva, como se ve en cierto sentido impuesta por un conjunto de circunstancias, nos obligan a replantear nuestro sistema de empleo público que, globalmente, parece más pensado para responder a las necesidades de una sociedad y a una Administración de otra época, pero no de la era post-industrial, tecnológica y telemática, cambiante y de incertidumbre en que nos movemos en la actualidad. Y los datos son más que concluyentes al respecto. En efecto, los estudios realizados han puesto de manifiesto, en más de una ocasión, el desencuentro que, con justificación o no, existe entre nuestra ciudadanía y la función pública española. De esta forma, se ha puesto de relieve la percepción de la ciudadanía de que el funcionamiento de la Administración es uno de los elementos que menos se ha transformado en España en los últimos años; que los funcionarios son, en una proporción importante, autoritarios y lentos en su trabajo; que los aspectos que menos han mejorado en la Administración pública en los últimos años son la rapidez, la sencillez del procedimiento o la actitud del funcionario al ciudadano; o, por ofrecer un último dato, que los ciudadanos no perciben nítidamente la imparcialidad de los 


\section{funcionarios en el ejercicio de sus funciones y estiman que suelen establecer distincio-} nes tratando mejor a las personas de clase alta, a familiares y amigos ${ }^{53}$.

Los conceptos clásicos de responsabilidad y jerarquía referidos de forma uniforme al conjunto de la función pública española, bases en las que hemos funda-

53 Distinta es la percepción de la ciudadanía cuando son preguntados por los servicios públicos. Si nos atenemos a los resultados que se consiguen la Agencia Estatal de Evaluación de las Políticas Públicas y la Calidad de los Servicios puso en su día de relieve, en un informe de percepción ciudadana correspondiente al ejercicio de 2010, que entre un 60 y un 70\% de los ciudadanos se sentían satisfechos con los transportes, la sanidad, la educación, los servicios sociales y la seguridad ciudadana o que más de un 80\% consideraban que funcionaban mejor que hasta hace cinco años o. en fin, y por dar un último dato, algo más del 75\% de los ciudadanos se sentía muy o bastante satisfecho con su última experiencia en un servicio público de tipo administrativo y más de un $80 \%$ vio colmadas sus expectativas pues afirmaban que se les trató mucho mejor, mejor o más o menos igual de lo que se esperaban.

No era casualidad. En contra de algunas opiniones instaladas en la cultura ciudadana, lo cierto es que la preparación, el alto grado de profesionalización y las capacidades de nuestro empleados públicos están a un nivel muy razonable en relación con los países de nuestro entorno y son muy superiores a los de muchos países del orbe.

Estos datos, es obvio, arrojaron resultados más negativos en los años más duros de la crisis económica, pero En 2014 y continuando la tendencia iniciada en 2013, se estabilizó el nivel de insatisfacción con los servicios públicos en general, aunque todavía una mayoría de los encuestados consideraban que los servicios públicos en general funcionaban de manera poco o nada satisfactoria.

Un dato importante a anotar, que se recoge en este Informe referido a 2014, es que como en años pasados, y a diferencia de lo que ocurre con las políticas y servicios de carácter sectorial, el porcentaje de ciudadanos satisfechos con la experiencia de prestación en los doce meses anteriores de servicios horizontales o administrativos en una oficina de la administración pública seguía siendo muy elevada. Para la gran mayoría de la población, la atención recibida en los servicios administrativos presenciales había cumplido sus expectativas.

Los atributos de los servicios administrativos presenciales mejor valorados eran: el estado de las instalaciones, el trato que recibió el ciudadano y la profesionalidad del personal que los atendió. El peor valorado es el tiempo de espera hasta ser atendidos, cuya influencia, sin embargo, en el grado de satisfacción global era mínima.

Para 2015 se produjo una leve mejoría de la percepción de la ciudadanía sobre los mismos. La mitad de los españoles se declararon ya satisfechos con el funcionamiento de los servicios públicos, independientemente de su titularidad, lo que suponía una mejoría respecto a los pasados ejercicios, y un cambio en la tendencia negativa que se había iniciado en 2012. Este cambio se percibía también en la evaluación retrospectiva de la evolución de los servicios públicos en los últimos cinco años, aunque todavía sólo una cuarta parte de la población opinaba que habían mejorado.

Los más satisfechos eran los ciudadanos mayores de 65 años, independientemente del género, los extranjeros, los estudiantes y los que tienen un mayor nivel formativo, además de, como es habitual, los que se ubicaban a la derecha en la escala de autoposicionamiento ideológico. Los más insatisfechos eran los ciudadanos en situación de desempleo y los de mediana edad.

Este aumento del nivel de satisfacción, razonaba el Informe, iba ligado al aumento del nivel de importancia que los ciudadanos atribuían a los servicios públicos, que ya era muy elevado, y que en 2015 alcanzó a más del 90\% de los españoles que lo sitúan por encima del 7 en una escala de 1 a 10.

En fin, y en conclusión, en la percepción de los ciudadanos las políticas públicas, con las necesarias excepciones y con carácter general, en los años en que se han producido las políticas más intensas de ajuste fiscal se habían deteriorado respecto de los datos iniciales de los que se había partido, si bien en los dos últimos años se había iniciado una todavía leve mejoría en la percepción de éstos. 
mentado la organización de nuestra burocracia pública, no ofrecen en la actualidad respuestas, sino muy limitadas, para atender los requerimientos que a nuestro sector público le exigen ese conjunto de circunstancias a las que antes nos referíamos. Se hace preciso la introducción de nuevas claves y de nuevas herramientas y despojarnos de ciertos mitos y tabúes para afrontar la exigencia de resultados que una sociedad madura y desarrollada plantea a nuestras Administraciones públicas. Es necesario, pues, un nuevo concepto de responsabilidad que realce, al menos en igual medida, la consecución de metas y objetivos con el respeto ineludible y necesario en una sociedad democrática a los principios de legalidad y de seguridad jurídica. Es decir, es preciso que pensemos sobre el exceso de reglas formales en nuestros procedimientos (derivadas, bien es verdad, de la desconfianza existente hacia nuestros responsables públicos que en más de una ocasión, como hemos podido apreciar en los últimos años, la justifican) y los efectos contradictorios, y en algunos casos meramente retóricos, que pueden provocar, con la ausencia, en forma paralela, de mecanismos reales de exigencia de responsabilidad basada en los resultados para nuestros responsables y servidores públicos.

\section{Aspectos claves del proceso de reforma.}

La observación de la realidad actual en el campo público, y no solo en la Comunidad Autónoma de Andalucía, refleja, con carácter general, un panorama necesitado de un replanteamiento y un nuevo impulso (no meramente normativo aunque también normativo como estamos exponiendo). La gestión de los recursos humanos se realiza prácticamente en ausencia de establecimiento de objetivos o plan alguno, sin evaluación de los resultados, sin definición clara de las unidades orgánicas, en medio de la ausencia de una política de recompensa/sanción y sin una política salaria claramente definida, con un importante déficit en los mecanismos de racionalización y reasignación de efectivos en la que hasta la crisis económica solo operaba con una lógica incrementalista, con una utilización de la formación en que sólo se tienen en cuenta los intereses de desarrollo personal de los miembros de la organización, etc... ${ }^{54}$

En definitiva, con carencias relevantes en la definición de una política estratégica de gestión de los recursos humanos que prime, al menos, cuatro factores esenciales, a saber: el apoderamiento de las personas (empowerment), es decir, ya no puede ser que unos piensen y otros ejecuten, sino que por el contrario toda la organización ha

54 Puede verse, en un excelente análisis, el trabajo de LOSADA, C., ALBAREDA, A. FÉREZ, M. Y LONGO, F., El empleo público en España: Desafios para un Estado Democrático más eficaz”, IEE, 2017. Asimismo, LOSADA, C., Aproximación a un diagnóstico y sugerencias de mejora del empleo público en España, Revista Vasca de Gestión de Personas y organizaciones públicas, n 13, 2017, págs. 8-25 o, por último, AAVV Nuevos tiempos para la función pública. Propuestas para atraer y desarrollar el talento en la Administración General del Estado, Madrid, INAP, 2017. 
de apoyar la creatividad; identificación y despliegue de políticas, en el sentido de que cada persona ha de saber en qué contribuye a la organización y ser retribuida por ello; información y comunicación de los objetivos de la organización; y, por último, desarrollo del conocimiento y las competencias de la organización utilizando la formación como elemento clave para ello, abandonando su desconexión de las políticas de personal en su conjunto y su planificación desligada de la detección de necesidades.

La respuesta a estas cuestiones pasa por realizar necesariamente un análisis más exhaustivo de los problemas que aquejan a la función pública autonómica, junto a los ya referidos, y que en nuestra opinión han de encontrar una solución adecuada. Nosotros daremos cuenta de algunos que desde nuestro punto de vista pueden ser claves en la mejora del empleo público andaluz y que podrían justificar la necesidad de un nuevo marco normativo.

Una primera reflexión que ha de realizarse se centra, y ya lo hemos apuntado, en torno a quienes deben de ser los destinatarios de la norma. Es obvio, y así ha quedado expuesto, que la actual norma legal es insuficiente en su aplicación a otros colectivos, léase principalmente personal al servicio de los Gobiernos locales de Andalucía, y que ese debe ser precisamente un punto principal en el eje de las reformas que han de realizarse. Como ya ha quedado dicho el empleo público para el que se pensó la actual Ley de Función Pública suma aproximadamente unos doscientos cincuenta mil efectivos, pero prácticamente al margen de la misma, o al menos sin atender específicamente a éstos, quedan de un lado 122.000 efectivos de la Administración local de Andalucía y aproximadamente 26.000 de las Universidades andaluzas. Una nueva norma no debería dictarse sin atender específicamente la problemática de estos colectivos y con la intención de establecer un sistema de movilidad interadministrativa y unos equilibrios entre los distintos colectivos en relación a las condiciones de trabajo, en términos de equidad externa e interna, con independencia de su adscripción a una u otra Administración pública

Casi a renglón seguido, la propia organización de la función pública andaluza resulta ser otro elemento que ha de ser objeto de especial interés. La racionalización de los cuerpos de funcionarios existentes y su mayor conexión con el sistema de puestos de trabajo, el establecimiento de mecanismos adecuados para la distribución de efectivos, la ruptura del dogma de adscripción indistinta de los puestos de trabajo, un mejor funcionamiento de las áreas funcionales etc. son elementos, entre otros muchos, que deberían ser considerados.

La creación de estructuras directivas profesionales se presenta también como un punto a ser debatido y considerado. Es claro que en la actualidad existe un déficit en la generación de funciones directivas. Nuestro modelo de función pública carece en gran medida de directivos públicos. El propio modelo actual de organización y de 
función pública, articulado en el dualismo responsables políticos-funcionarios, no los produce. Ni la selección y provisión de puestos de trabajo se dirige a ello, ni existen los mecanismos necesarios que la hagan viable: evaluación, formación, definición de funciones y garantía de las mismas, etc. Y, sin embargo, los requerimientos exigidos a nuestras Administraciones públicas demandan, cada vez con mayor insistencia fruto de la expansión en la prestación de servicios públicos que ha acontecido en los últimos tiempos, la articulación de una función directiva, que sobre todo en aquellos sectores donde se demandan resultados en términos de prestaciones a los ciudadanos, asuma actitudes más gerenciales, por supuesto dentro del aseguramiento de los bienes públicos y la especificidad de lo público que requiere este sector, y con ello un mejor servicio a los destinatarios de los servicios prestados con un paralelismo de racionalización y responsabilidad en la gestión.

El sistema selectivo también ha de ser objeto de consideración. Debemos tener en cuenta que uno de los dos contenidos que el art. 136 determina para el legislador autonómico en materia de función y empleo públicos es «el acceso al empleo público de acuerdo con los principios de mérito y capacidad», precepto que debe relacionarse con el art. 26.1 b) EAA, el cual declara garantizar a todas las personas el acceso al empleo público en condiciones de igualdad y según los principios constitucionales de mérito y capacidad. La única novedad que suponen tanto el art. 136 como el art. 26.1 b) EAA consiste en imponer los principios de mérito y capacidad no ya al acceso a la «Función pública» sino al «empleo público», noción más amplia, que engloba también al personal laboral de las administraciones públicas.

¿Pero es esto todo?. Me temo que no. En primer término, carecemos en el sector público de medios precisos para identificar las necesidades de personal a medio y largo plazo, y no sólo en el aspecto cuantitativo sino sobre todo en el cualitativo. En segundo lugar, los procedimientos selectivos son costosos, de discutible validez y finalidad y, por si fuera poco, lentos (desde que una unidad organizativa decide cubrir una vacante hasta que el funcionario efectivamente se incorpora pueden transcurrir de 10 a 24 meses). En segundo lugar, el sistema selectivo ha de garantizar, que no lo hace plenamente en la actualidad, su adecuación a las funciones que han de ser efectivamente desarrolladas con posterioridad. La valoración de otros elementos distintos a los conocimientos como las aptitudes personales y las habilidades sociales deben encontrar asimismo un cauce dentro de los sistemas generales de acceso (oposición y concurso-oposición) ya que el éxito de la organización va a depender en buena medida de éstos. De otro lado, es preciso concebir el proceso selectivo como un procedimiento que no finaliza con la realización de unas pruebas selectivas, sino que éstas, con las necesarias modificaciones que nos permitan mejorar su fiabilidad, se continúan con un proceso posterior de adecuación de la persona con la organización concreta y el puesto de trabajo a desempeñar y en el que la relación jurídica debe 
quedar condicionada, en cuanto a su mantenimiento, al éxito en dicha adecuación. La posibilidad de que no se seleccionen únicamente el número de candidatos que se adecua al número de plazas ofertadas y la generación de una bolsa de empleo con los que efectivamente las superen que permita realizar estos procedimientos debe ser seriamente considerada.

El sistema de carrera administrativa y de promoción profesional ha de ser también objeto de reflexión. Centrándonos en el actual sistema algunos puntos pueden ser apuntados: 1) Los mecanismos de provisión siguen articulando carreras administrativas de tipo burocrático que no se adecuan a numerosos sectores de actividad de nuestra Comunidad Autónoma; 2) La carrera administrativa tiene poca repercusión en el monto total retributivo de forma tal que, en ocasiones, se produce una doble carrera a través del complemento específico; 3) La estructuración de la misma ha favorecido la inflación organizativa no justificada lo que, a su vez, ha dificultado políticas de promoción interna más activas al compensarse por la provisión de puestos de trabajo; 4) Todavía subsiste una cierta falta de transparencia y arbitrariedad en la provisión de puestos de trabajo; 5) Abuso de los sistemas provisionales de provisión de los puestos de trabajo a fin de facilitar, con posterioridad, la consolidación de dichas situaciones.

La reconsideración general de todo el sistema de recompensas (ya sean retributivas o de otro tipo) y del sistema de penalización de aquéllas conductas que no favorecen la mejora de la gestión de los servicios ha de ser otro punto clave a considerar. El sistema retributivo, el régimen disciplinario y otros elementos atinentes al sistema de motivación de los empleados públicos han de ser necesariamente revisados. Existe algún margen en las bases establecidas por el EBEP para hacerlo y éste ha de ser aprovechado ya que la realidad actual ofrece resultados bastantes pobres en cuanto a la eficacia del mismo.

Ajustar la actual definición de derechos y deberes a nuevos requerimientos: conciliación de vida familiar y laboral, nuevas formas de prestación de trabajo, la participación en la definición de objetivos, etc.. pero sin olvidar, también, la necesidad de estructurar también claramente una tabla de deberes y un marco de desarrollo de la integridad profesional que responda a las exigencias de servicio que el ciudadano plantea a nuestras Administraciones públicas (controles de calidad, cartas de servicios, reestructuración del sistema de responsabilidad, etc...) es un punto necesitado de nuevos desarrollos normativos.

Otro punto importante es la necesidad de mejorar los medios extrajudiciales de solución de los conflictos. A nadie se le oculta la alta conflictividad, tanto en las relaciones laborales como funcionariales, que padecen nuestras Administraciones públicas y que alcanza, en un correlato lógico, a los órganos jurisdiccionales ya sean 
las Salas de los Tribunales Superiores de Justicia o los Juzgados de lo Contencioso-Administrativo de reciente creación. Sin embargo, dicho estado de cosas no es satisfactorio ni para los empleados públicos que aprecian que abusos manifiestos no tienen una solución pronta y satisfactoria, ni para los tribunales que se ven abocados a resolver imperativamente conflictos que podrían tener otras vías de solución, pero ni, inclusive, para las propias organizaciones públicas cuya actuación en este concreto aspecto no potencia la motivación de los empleados públicos y, en ocasiones, ofrecen una sensación de abuso injustificable en la toma de decisiones, articulada de forma unilateral en la mayoría de los supuestos, que no favorece la armonía en las relaciones laborales.

Y es que el segundo de los contenidos que el art. 136 EAA determina para el legislador autonómico en materia de función y empleo públicos consiste en establecer «un órgano administrativo de la Función pública resolutorio de los recursos que se interpongan sobre esta materia». Interpretado en un sentido literal, tal precepto podría no significar nada, pues como se ha señalado acertadamente por ESCRIBANO $\mathrm{COLLADO}^{55}$, en puridad, tal órgano administrativo de la Función pública resolutorio de los recursos que se interpongan sobre esta materia ya existe: la consejería competente en materia de empleo público. Ahora bien, como se señaló más arriba, el texto que sirvió de origen a este precepto hablaba de un «tribunal administrativo de la función pública», término que se suprimió por el más aséptico de «órgano», para satisfacer una enmienda. Sin embargo, bien podría haberse añadido alguna matización adicional, en el sentido de órgano de composición técnica y dotado de autonomía funcional ${ }^{56}$.

${ }_{55}$ ESGRIBANO COLLADO, P., La administración pública de la Comunidad Autónoma de Andalucía, Revista Andaluza de Administración Pública, nº. Extra 2, 1, 2003

56 De hecho, su necesidad ha sido constatada por el Defensor del Pueblo Andaluz que en el expediente 13/1859 (2013) concluye que "Por ello, y como así fundamentamos en la admisión a trámite de la queja de oficio, a cuyo acto nos remitimos, nos dirigimos a la titular de la Consejería de Hacienda y Administración Pública considerando que llegado es el momento de que se considere la conveniencia de promover las iniciativas legislativas o reglamentarias precisas en orden a articular el órgano resolutorio de los recursos en materia de empleo público se planteen por los servidores públicos dependientes del sector público andaluz". Y añade que "debemos significar que la paulatina creación de órganos específicos para ejercitar la actividad revisora de la Administración de la Junta de Andalucía, como hemos visto en la materia de contratación pública y tributaria, precisa de un paso más, y esta vez en el ámbito de la gestión del personal público dependiente de la Administración general e instrumental de la Junta de Andalucía, tal y como mandata el art. 136 del Estatuto de Autonomía de Andalucía, y ello no solo por este imperativo legal sino también por así exigirlo el notable volumen de recursos contencioso-administrativos que se presenta en los correspondientes juzgados y salas del Poder Judicial en Andalucía, casuística a los que no es ajeno este Comisionado parlamentario, ante el que suele presentarse alrededor de un millar de quejas anuales en esta materia (procesos selectivos, bolsas de empleo, concursos de traslados, retribuciones, condiciones de trabajo, etc.)". 
Estos elementos, junto a otros que podrían ser citados, justifican de por sí la apuesta por una nueva normativa. Pero dos reflexiones han de realizarse ineludiblemente.

La primera relativa a que ciertamente, como sucedió en su día con la actual Ley de función pública andaluza, el escenario ideal sería aquél en que el Estado hubiese ejercitado sus competencias sobre el empleo público de forma integral dando cumplimiento al artículo $103 \mathrm{CE}$ a fin de disponer de los referentes necesarios para acometer la necesaria reforma del marco normativo Andaluz. Pero, como también se ha expuesto, la sociedad andaluza, su Administración dada la importancia estratégica que representa para dicha sociedad, tampoco puede quedar a la aparentemente eterna espera del mismo dadas las dificultades y ausencia de consenso que presenta la redacción de éste. El nuevo impulso que se necesita ha de partir, por tanto, de lo existente hasta ahora sin esperar, al menos por el momento, a un improbable Estatuto de la Función Pública. Apurando al máximo las posibilidades normativas y con un proyecto claro y transparente que dé respuesta a las claves enunciadas.

La segunda, evidente en sí misma pero que a la postre determinará el éxito de las reformas que se emprendan, es que no es posible pensar que basta una reforma legal. Eso será un primer paso, pero lo verdaderamente relevante será el rigor con se apliquen éstas y el cambio de cultura administrativa que exigen para su éxito. Y eso será, con todas las reformas legales que se quieran, sin duda el punto de equilibrio para el éxito de los cambios que nuestro empleo público demanda. Efectivamente, PRATS ha puesto de relieve la necesidad urgente, para que las reformas del Estado alcancen el éxito que se espera de las mismas, de que se produzca un cambio institucional ${ }^{57}$. Quiere decir ello, en palabras de dicho autor, que "las organizaciones estatales no son libremente disponibles; contrariamente, se encuentran ampliamente sobredeterminadas por el tipo de institucionalidad pública existente, es decir, por las normas y reglas -formales e informales- que establecen los fines, límites, actores, procedimientos y formas de participación en la acción colectiva, así como por los correspondientes modelos mentales, actitudinales y valorativos que prestan legitimidad, permiten la vigencia y dificultan el cambio de tales reglas y normas". De todo lo cual deduce el autor una conclusión: "si la institucionalidad pública es el marco de incentivos de las organizaciones públicas, cualquier reforma de éstas sólo será positiva y duradera en la medida en que contribuya a reformar también positiva y duraderamente el fondo o marco institucional en que la organización se inserta" y, correlato de lo anterior, que si reconocemos como cierto lo expuesto la reforma del sistema de empleo público no puede ser solamente una operación meramente técnica

57 PRATS I CATALÁ, J. Reforma del Estado y desarrollo humano en América Latina, Quórum: revista de pensamiento iberoamericano, $\mathrm{N}^{\circ} 1$ (S), 2000 (Ejemplar dedicado a: El Estado, otra vez), págs. 41-61 
sometiéndola a una lógica de cambio perfectamente planificado, sino que va a requerir también de un proceso constante, dilatado a lo largo del tiempo, que modifique también aquellos elementos subyacentes que en forma inercial permanecen en el empleo público sea cual sea la norma legal o reglamentaria que se dicte. 